\title{
LOS INICIOS DE LA CONQUISTA ROMANA DE IBERIA: LOS CAMPAMENTOS DE CAMPAÑA DEL CURSO INFERIOR DEL RÍO EBRO
}

\author{
POR \\ JAUME NOGUERA GUILLÉN \\ Investigador Beatriu de Pinós ${ }^{1}$ (ICAC) ${ }^{2}$
}

\begin{abstract}
RESUMEN
La investigación arqueológica de los campamentos de campaña romano-republicanos localizados en el curso inferior del río Ebro permite una nueva perspectiva de estudio sobre los inicios de la conquista romana en la península ibérica.
\end{abstract}

\section{SUMMARY}

Archaeological research of the Roman-Republican military camps identified along the lower course of the Ebro river brings a new perspective of study of the beginnings of the Roman conquest in the Iberian Peninsula.

PALABRAS CLAVE: Prospecciones arqueológicas. Ejército romano. Segunda Guerra Púnica. Rebeliones indígenas. La Palma (l'Aldea, Tarragona). Camí del Castellet de Banyoles (Tivissa, Tarragona).

KEY WORDS: Archaeological prospections. Roman army. Second Punic War. Indigenous rebellions. La Palma (l'Aldea, Tarragona). Camí del Castellet de Banyoles (Tivissa, Tarragona).

\section{INTRODUCCIÓN}

El objeto de este artículo es presentar la documentación arqueológica más reciente sobre los primeros momentos de la conquista romana en la península ibérica. Esta aportación se basa en los resultados iniciales de las prospecciones arqueológicas en dos yacimientos del curso inferior del río Ebro: la Palma (l'Aldea, Tarragona) y el Camí del Castellet de Banyoles (Tivissa, Tarragona).

El proyecto de investigación sobre los campamentos militares de época republicana en el bajo Ebro $^{3}$

\footnotetext{
${ }^{1}$ Comissionat per a Universitats i Recerca del Departament d'Innovació, Universitats i Empresa de la Generalitat de Catalunya.

${ }^{2}$ Institut Català d'Arqueologia Clàssica, Tarragona.

3 Financiado por la ayuda 2007ACOM 00030 de la AGAUR, el Ayuntamiento de Tarragona, el Departament de Cultura de la Generalitat de Catalunya y l'Institut d'Estudis Ramon Muntaner.
}

se inició el año 2006. Hasta el momento se han realizado dos campañas de prospección en la Palma y una en el Camí del Castellet de Banyoles. Los resultados son preliminares, pero sugieren que se trata de sendos campamentos romanos de campaña, el primero de la Segunda Guerra Púnica, el segundo datable durante el primer decenio del siglo II a.C. (Fig. 1).

El conocimiento de los establecimientos militares temporales en la península ibérica ha progresado enormemente en los últimos años (Morillo 2003). Entre estos asentamientos, los campamentos de campaña son los que presentan un carácter más provisional, ya que pueden tener una duración muy corta, de tan sólo un día, o de meses o incluso años, todo depende de consideraciones estratégicas y de la duración del conflicto. Su construcción responde a criterios de eventualidad y por ello generalmente fueron levantados con materiales ligeros, de fácil y barata obtención como la madera, la tierra, etc. Por su corta duración y por el carácter perecedero de estos materiales, son yacimientos casi invisibles, muy difíciles de identificar. Ello explica su escasez generalizada y hasta fechas muy recientes los datados entre finales del siglo III e inicios del siglo II a.C. eran prácticamente desconocidos.

En cambio, las fuentes escritas hacen continua referencia a su existencia durante las diferentes campañas de la Segunda Guerra Púnica. Sin ánimo de ser exhaustivos, podemos mencionar los 8000 soldados estacionados en el campamento de Sucro en el 206 a.C. (Livio XXVIII, 24, 5). Igualmente hay que señalar el establecimiento de un campamento situado en la desembocadura del Ebro, con tropas sucesivamente comandadas por Lucio Marcio (Livio xxv, 37, 6-7), Claudio Nerón (Livio XXVI, 2) y Publio Cornelio Escipión (Livio XXVI, 41, 1-2). Asimismo, hay que recordar que entre Tarraco y el Ebro también se establecieron otras guarniciones, probablemente de menor entidad (Livio XXVIII, 42, 3-4). Además, era 


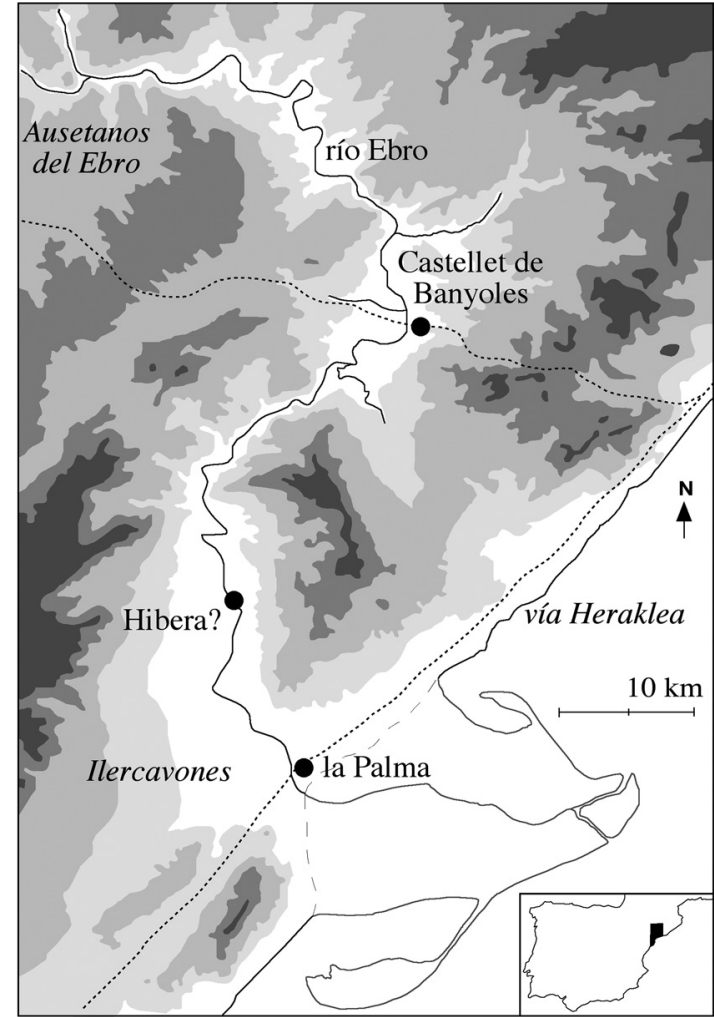

Fig. 1. Mapa del curso inferior del río Ebro, con la situación de los campamentos de la Palma y del Camí del Castellet de Banyoles, ambos junto a importantes vías de comunicación.

un práctica habitual de los ejércitos púnicos y romanos dispersar las fuerzas en los campamentos de invierno y reagruparlas a inicios de la primavera para iniciar una nueva campaña (Polibio III, 95,3; Polibio X, 37, 6; Livio XXv, 32, 1; Livio XXVI, 41, 2; Livio XXIX, 2, 1).

Como ya hemos comentado, la constatación arqueológica de este tipo de asentamientos es escasa y muy reciente. Para el período que nos ocupa hay que destacar la investigación de los campamentos relacionados con la batalla de Baecula en el 208 a.C., alrededor del Cerro de la Albahacas (Santo Tomé, Jaén). El yacimiento está en proceso de estudio, por lo que aún se conocen pocos datos, pero sobre todo destaca su gran extensión, justificable por tratarse de un gran campo de batalla (Bellón et alii 2002-03).

Por otro lado, el proyecto de investigación centrado en la ciudad celtibérica de Ségeda parece haber localizado en los Planos de Mara el campamento romano que sitió la ciudad en el 153 a.C. Se trata de una altiplanicie con una extensión aproximada de 10 hectáreas, donde no se aprecian estructuras cons- truidas, pero sí una gran dispersión de materiales cerámicos, principalmente ánforas contemporáneas a las documentadas en el campamento de Nobilior en Renieblas. La topografía, extensión y situación del yacimiento, el tipo de evidencias cerámicas y su dispersión, son elementos que inducen a sus investigadores a considerarlo un campamento de campaña (Burillo 2007, 285).

A estos dos asentamientos militares podríamos añadir otros probablemente relacionados con la campaña de Catón, pero de difícil concreción cronológica, como el campamento Rasa junto a Numancia (Morales 2007, 271) o el campamento I de Renieblas (Luik, Müller 2006). Finalmente, fuera del período cronológico contemplado, pero muy interesantes desde el punto de vista conceptual, son los castra aestiva de la cornisa cantábrica de finales del siglo I a.C. (Peralta 2002).

\section{LA SEGUNDA GUERRA PÚNICA EN EL BAJO EBRO}

El principal escenario de los combates durante la fase inicial de la Segunda Guerra Púnica en la península Ibérica fue el curso inferior del río Ebro. Por lo tanto, en esta zona han de localizarse los campamentos de campaña de las tropas romanas y cartaginesas entre el 218 y el 209 a.C.

Uno de estos campamentos, quizás el más importante de las tropas romanas destacadas en la zona, es el de la Palma (l'Aldea, Baix Ebre). El yacimiento se sitúa en la ribera izquierda del Ebro, junto a su antigua desembocadura, sobre una terraza fluvial a unos quince metros de altura sobre el río (Fig. 2). Hay que recordar que el delta es una formación posterior a la época romana e incluso se ha especulado sobre la posibilidad de que el río dibujase un estrecho estuario entre Amposta y Tortosa, facilitando aún más su navegación. No entraremos aquí a defender las inmejorables condiciones geoestratégicas del lugar, paso obligado de todo tipo de comunicaciones (Noguera, en prensa). De hecho, en la actualidad el yacimiento ha sufrido continuas remociones de tierra debido a la construcción de diversos ejes viarios: por él discurren la autopista AP7, el ferrocarril BarcelonaValencia o el antiguo ferrocarril de Tortosa a la Cava. En relación con esta importancia no es de extrañar que el lugar fuera escenario de encarnizados combates durante diferentes períodos de la historia, por ejemplo durante la toma de Amposta por los carlistas o durante la batalla del Ebro de 1938, cuando tropas de la XIV Brigada Internacional realizaron un san- 


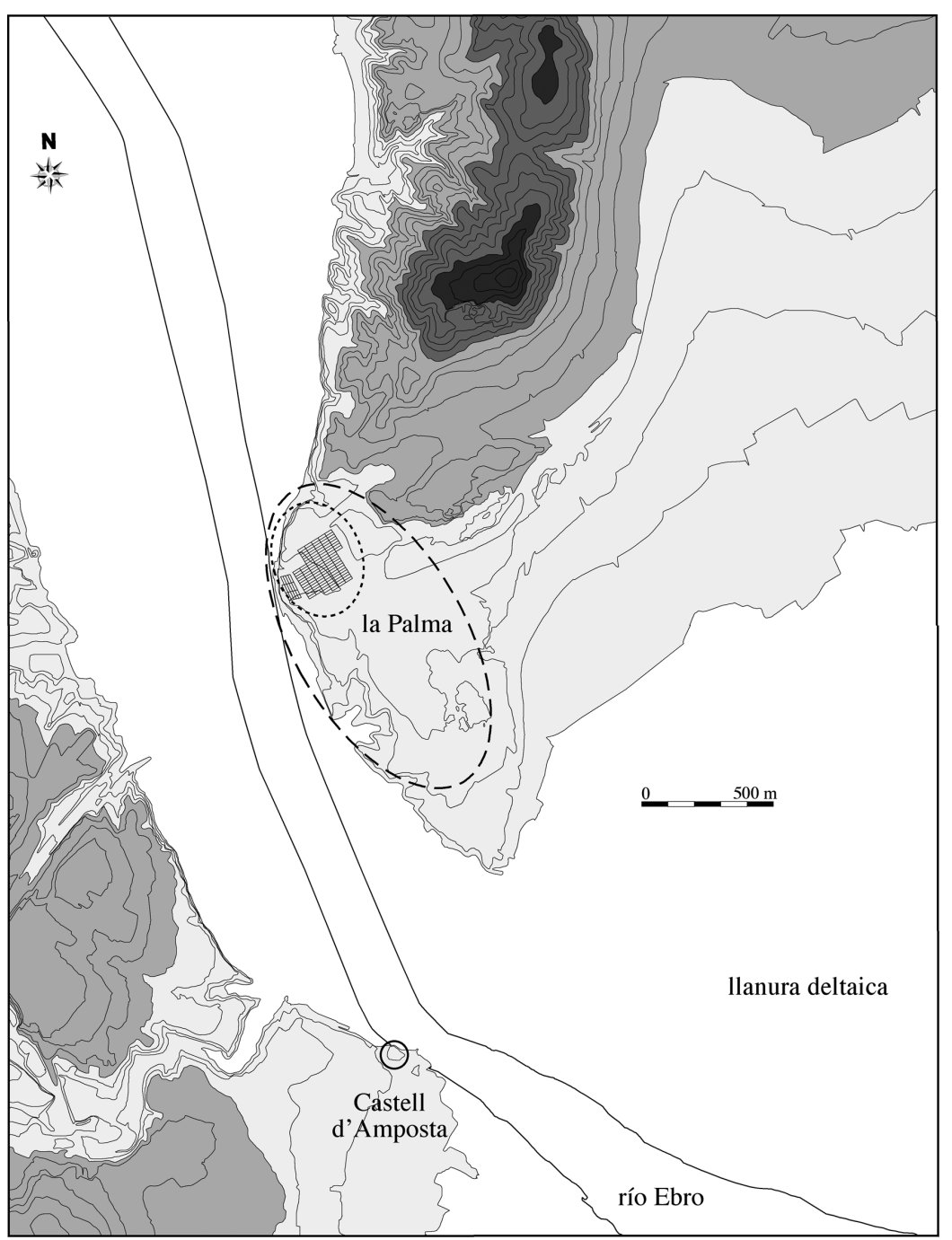

Fig. 2. Mapa de la antigua desembocadura del río Ebro, con la situación del campamento romano de la Palma. Las líneas discontinuas marcan la extensión máxima del asentamiento y la zona donde actualmente se realiza el trabajo de campo, con las unidades de prospección de la campaña de 2006.

griento ataque de diversión en esta zona. Como es de suponer, los trabajos de prospección han recuperado gran cantidad de proyectiles y metralla correspondientes a estos enfrentamientos.

Volviendo al período que nos ocupa, la dispersión de materiales arqueológicos de finales del siglo III a.C. sugiere una extensión del yacimiento que se podría aproximar a las $30 \mathrm{Ha}$, pero actualmente la transformación urbanística del entorno limita los trabajos de investigación a una superficie de unas $7 \mathrm{Ha}$.

El campamento ocuparía así un terreno llano, provisto de agua y bien comunicado. Sus límites naturales serían el escarpe de la terraza fluvial al Este, el curso de un antiguo barranco por el Norte y la línea de costa antigua por el Sur, mientras que por el Oeste el paisaje ha sido transformado profundamente, de manera que cualquier defensa artificial o límite natural habría desaparecido.

La primera campaña de investigación, realizada durante el mes de agosto de 2006, se centró en la prospección sistemática del yacimiento (Fig. 3). En la zona $\mathrm{A} 1$, de $17.000 \mathrm{~m}^{2}$, no se pudo trabajar por haberse convertido temporalmente en un vertedero incontrolado. La zona B1, de casi $40.000 \mathrm{~m}^{2}$, fue labrada superficialmente para facilitar la prospección visual. Posteriormente fue dividida en 131 unidades 


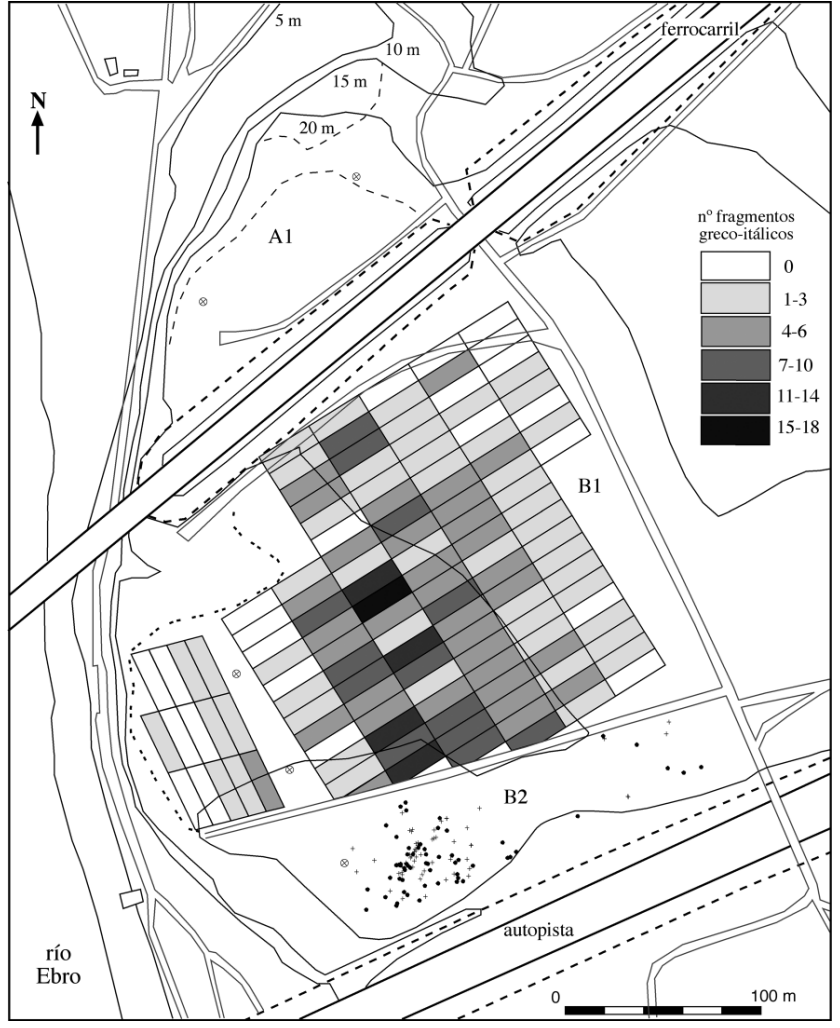

Fig. 3. Planta de las zonas prospectadas sistemáticamente en el yacimiento de la Palma, con el resultado de la prospección mediante el uso de transects de $300 \mathrm{~m}^{2}$ (zona B1) y mediante la georeferenciación de cada fragmento cerámico (zona B2). Los puntos corresponden a fragmentos de ánforas greco-itálicas, las cruces a fragmentos ibéricos.

de 30 metros de largo y 10 metros de ancho, que fueron prospectadas sistemáticamente por un equipo de siete personas, equipadas con detectores de metales. Se recogieron 419 fragmentos cerámicos, de los cuales el $72 \%$ corresponden a ánforas greco-itálicas, el $24 \%$ son ibéricos y un $4 \%$ son indeterminados. Finalmente, en la zona B2, de $10.000 \mathrm{~m}^{2}$, se realizó una prospección sistemática prescindiendo de transects, pero situando cada fragmento cerámico mediante una estación total. En este sector se recogieron 129 fragmentos, de los cuales el $54 \%$ corresponden a ánforas greco-itálicas, el $41 \%$ son ibéricos y un $12 \%$ son indeterminados. Como se puede apreciar, la presencia de fragmentos de ánfora greco-itálica en las zonas B1 y B2 es significativa, tanto en porcentaje como en dispersión.

Las ánforas greco-itálicas recuperadas tienen los pivotes macizos y alargados, con los bordes inclinados unos $45^{\circ}$ (Fig. 4), y se pueden datar entre finales del siglo III e inicios del siglo II a.C. (Lyding Will 1982). Hay que resaltar la ausencia total de vajilla de barniz negro campaniense A, y también que la mayoría de los fragmentos de cerámica ibérica corresponde a material de transporte y almacenaje. Finalmente, durante esta primera campaña únicamente se recuperaron tres monedas y tres glandes de plomo (Fig. 5).

La segunda campaña de prospección, realizada en septiembre de 2007, se concentró en una franja de terreno paralela al río Ebro de $15.000 \mathrm{~m}^{2}$, una zona donde la campaña anterior había detectado una especial concentración de materiales (Fig. 3). Previamente se rebajó el terreno unos $20-30 \mathrm{~cm}$ para intentar identificar estructuras constructivas. El resultado fue totalmente negativo, ya que no apareció ningún indicio de muros, fosos o agujeros de poste. En cambio, la prospección mediante detectores de metales proporcionó diversos glandes de plomo y fíbulas de bronce, pero sobre todo un lote de 24 monedas, de las cuales 17 fueron amortizadas durante la Segunda Guerra Púnica. Este conjunto aún está en estudio, pero podemos avanzar su composición. Se trata de cuatro bronces romano-republicanos acuñados entre el 217 y el 212 a.C., cinco monedas hispano-cartaginesas del 221-218 a.C., dos cartaginesas (una de ellas procedente de Cerdeña), un divisor de bronce de Massalia, y una dracma y cuatro divisores de Emporion, uno de ellos probablemente una imitación ibérica de un tetartemorion ${ }^{4}$. Las siete monedas restantes corresponden a tres piezas de Jaume I de la ceca de Valencia, una de Fernando VII, una del Bajo Imperio, una de la segunda mitad del siglo XIX y una moneda indeterminada.

Este conjunto de monedas es análogo en cronología y composición al lote en manos de coleccionistas particulares, estudiado recientemente junto a las tres monedas recuperadas durante la campaña de 2006 (Noguera, Tarradell, en prensa). De estas 103 piezas, 75 fueron amortizadas durante la Segunda Guerra Púnica. El lote está constituido por 31 monedas romano-republicanas, 25 hispano-cartaginesas, 7 cartaginesas, 1 divisor de Emporion, 1 divisor ibérico de imitación de Emporion, 3 tetradracmas helenísticas, 1 bronce de Hierón de Siracusa, 2 bronces de Neápolis, 1 de Gadir y 3 de Ebusus, aunque estas últimas podrían corresponder a la circulación del siglo II a.C.

Hemos podido identificar 3 monedas de plata y 28 de bronce de la República romana, acuñadas an-

\footnotetext{
${ }^{4}$ Estudio numismático a cargo de la Dra. N. Tarradell.
} 


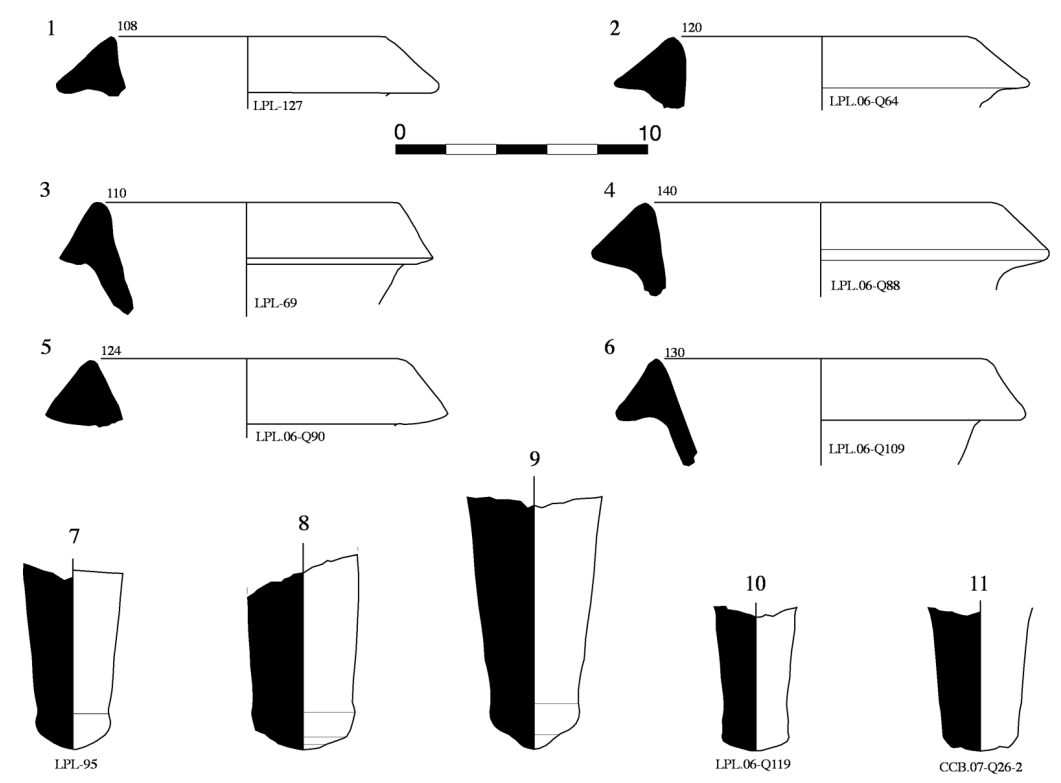

Fig. 4. Fragmentos de ánforas greco-itálicas procedentes de la Palma (campaña de prospección de 2006).

tes de la aparición del denario en el 211 a.C. Entre las monedas de plata destaca una didracma romanocampana de la emisión cabeza de Marte/cabeza de caballo -RRC 13/1- del 280-276 a.C. (Fig. 6, 3). Las otras dos monedas de plata son dos cuadrigatos acuñados entre el 225-212 a.C. —RRC 28/3-, poco gastados, por lo que parece que habrían circulado poco (Fig. 6, 4). Uno de los aspectos más excepcionales del yacimiento de la Palma reside en la abundancia de bronces romano-republicanos anteriores al 215 a.C., poco documentados hasta ahora en la Península y que habitualmente se relacionan con la presencia de tropas romanas. Hay que destacar un quadrans y un sextans de la serie RRC 35 del 225217 a.C., fabricados con la técnica de fundición (Fig. 6, 5-6). Pero el lote más abundante corresponde a las monedas de los años 217-215 a.C., formado por 18 bronces de la emisión RRC 38 y 8 bronces de la emisión RRC 39, concretamente quince uncias, nueve semiuncias, un quadrans y un sextans (Fig. 6, 7-12).

El segundo conjunto más numeroso está constituido por 25 monedas de bronce hispano-cartaginesas. Hemos identificado 20 monedas de la emisión Villaronga, 1973, clase VIII, datadas entre el 221-218 a.C.: 7 unidades del tipo I, cabeza de Tanit coronada de espigas/cabeza de caballo, y 10 unidades y 3 divisores del tipo II, de estilo tosco. La clase X está representada por tres unidades y un divisor, y la clase XI por un solo ejemplar (Fig. 7, 9-14).

El resto de las monedas del bando púnico corres- ponden a tres monedas de la ceca de Ebusus (Fig. 7, 6), un divisor de Gadir (Fig. 7, 7), y siete monedas cartaginesas. De estas últimas, dos pertenecen a la ceca de Cartago (Fig. 7, 8), un divisor SNGSassar 260265 de finales del siglo IV a fines del siglo III a.C., tres divisores aún no clasificados y una moneda en muy mal estado con el cospel fundido con una sola valva.

En cuanto a las monedas griegas de plata, hemos podido identificar tres monedas helenísticas del Mediterráneo oriental, concretamente una tetradracma de Ptolomeo I o II (Fig. 7, 5), y dos monedas partidas, una de Lisímaco y la otra quizás de Alejandro Magno, datadas en el siglo III a.C. A estas monedas hay que añadir un divisor de Emporion con reverso de dos delfines (Fig. 7, 1), y una imitación ibérica de un divisor de Emporion con el reverso del Pegaso y símbolo delfín (Fig. 7, 2) acuñadas a finales del siglo III a.C.

Las monedas griegas de bronce destacan por su rareza. Se trata de dos monedas de Neápolis del 270250 a.C. (Fig. 6, 1), y de un bronce de Hierón de Siracusa (Fig. 6, 2). También podríamos añadir un lote de ocho pequeños bronces de diferentes emisiones de la ceca de Massalia, pero todas ellas de peso bajo y, por lo tanto, atribuidas a una cronología entre el 140 y el 40 a.C. (Brenot 1982), por lo que quizás no guardan relación con el asentamiento militar de la Segunda Guerra Púnica (Fig. 7, 3-4). Ahora bien, sorprende la relativa abundancia de monedas de Massalia entre las monedas del siglo II-I a.C., prácticamente testimoniales y que en cambio no exista 


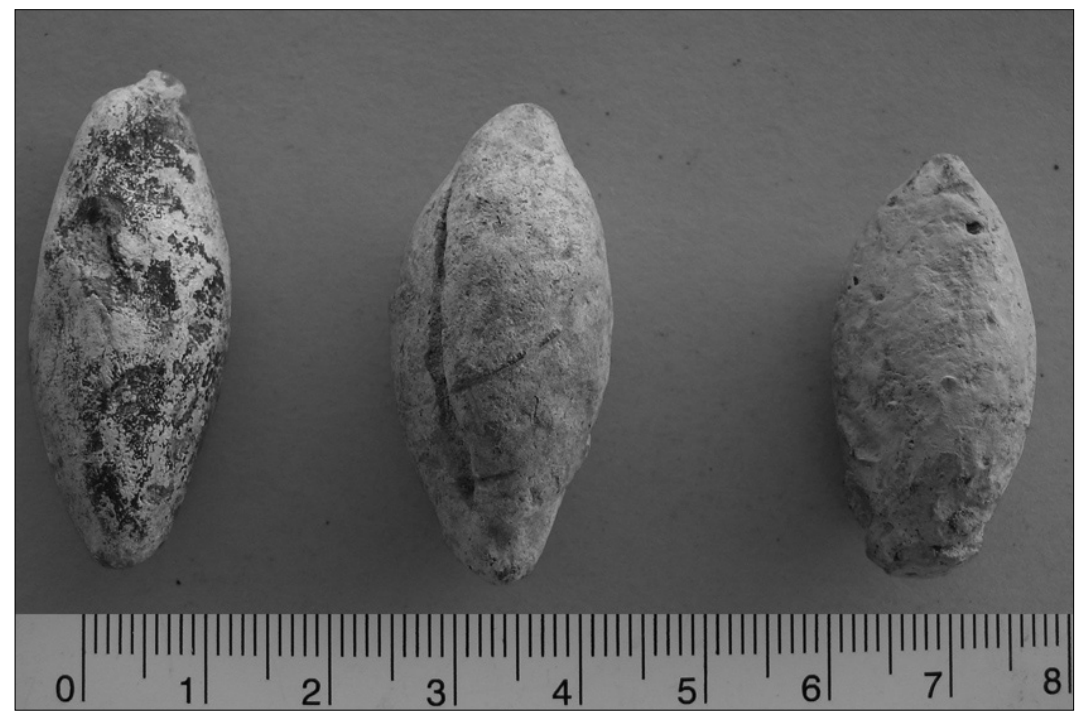

Fig. 5. Glandes de plomo procedentes de la Palma (campaña de prospección de 2006).

ni un sólo ejemplar de cronología más antigua. Finalmente, podemos añadir una moneda de bronce de Arse que también podría haber sido amortizada a finales del siglo III a.C. El hallazgo reciente e inédito ${ }^{5}$ de una pieza similar en el poblado ibérico de els Estinclells (Verdú, Lleida), en un contexto arqueológico fechado en la misma época, permite encuadrarla entre el lote de monedas antiguo.

El resto de las monedas, que no trataremos aquí, está formado por acuñaciones ibéricas y romanas de finales de la República y del Alto Imperio. Estas monedas, en una cantidad meramente testimonial, vienen a confirmar que la terraza de la Palma fue continuamente ocupada, seguramente en relación con su posición estratégica sobre un nudo de comunicaciones, y en particular con la probable existencia de un paso del río Ebro por este lugar.

Como podemos observar el conjunto es excepcional y prácticamente no podemos compararlo con ningún otro yacimiento conocido. Es importante destacar que del total de 92 monedas recuperadas hasta el momento y amortizadas con toda seguridad a finales del siglo III a.C., únicamente 13 son de plata. El hecho de que predominen las monedas de bronce de poco valor confirma que se trata de un lugar donde las monedas están en uso y circulación y que no es un ocultamiento.

Se trata de un conjunto numismático coherente con los hechos narrados en las fuentes: monedas romano-

\footnotetext{
5 Agradecemos a los directores de la excavación esta información.
}

republicanas y de las ciudades griegas aliadas de Emporion y Massalia (Fig. 8). Por otra parte, las monedas púnicas son muy abundantes, especialmente las hispano-cartaginesas. Ello podría explicarse por las cuatro derrotas consecutivas que sufrieron los cartagineses en las proximidades: Cissa (218 a.C.), en la batalla naval del Ebro (217 a.C.), Hibera (216 a.C.) y quizás en Intibilis (215 a.C.), por lo que los romanos se habrían apoderado de sus pertrechos (Livio XXI, $60,9)$.

La cronología inicial de la Palma podría relacionarse con la estabilización del conflicto en la línea del Ebro en el 218 a.C., o bien a partir de la victoria naval romana en su desembocadura en el 217 a.C. En cualquier caso, su existencia parece segura en el 210209 a.C. La cronología final creemos que tiene que vincularse con la conquista de Cartago Nova en el 209 a.C., y el desplazamiento del conflicto hacia el sur.

Desde el punto de vista numismático, la ausencia de victoriatos, denarios, quinarios y sestercios sugiere que el conjunto fue amortizado en una fecha anterior a la aparición del sistema del denario en el 211 a.C. Pero las fuentes escritas son explícitas en cuanto a la presencia en el 209 a.C. de Publio Cornelio Escipión en la desembocadura del Ebro, con las nuevas tropas llegadas a la Península. Por lo tanto, si tenemos en cuenta la ausencia de estas monedas en la Palma, parece que estos refuerzos llegaron desprovistos del nuevo numerario. De hecho, ni siquiera en las etapas finales del conflicto Roma pagó a sus tropas de Iberia con las nuevas monedas. Hay que recordar la penuria económica de la República en 
$1(89)$
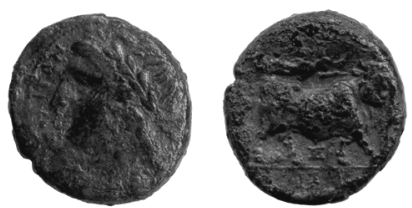

$3(1)$

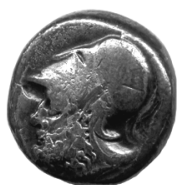

$4(2)$
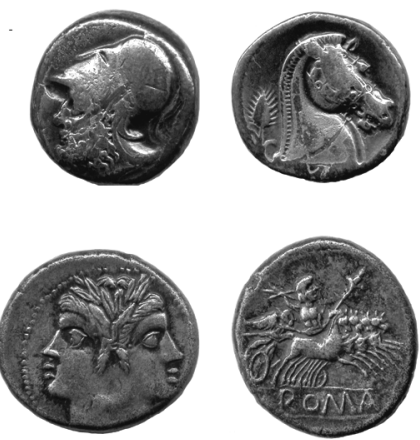

$8(21)$

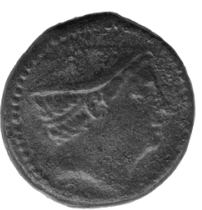

$9(29)$
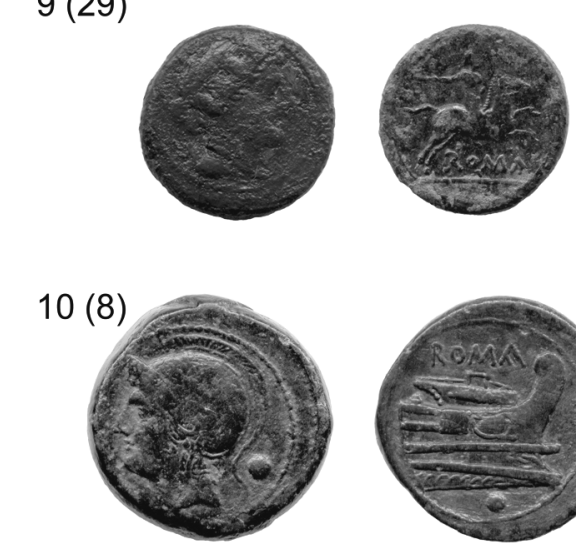

$10(8)$
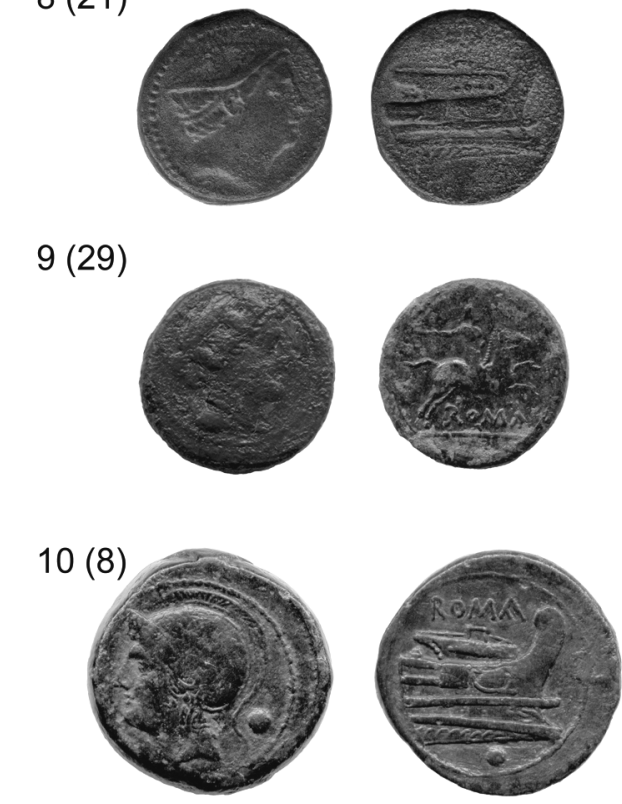

$12(25)$
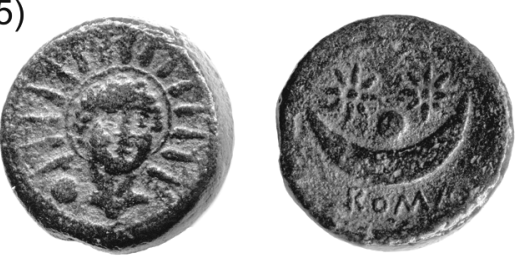

$2(93)$
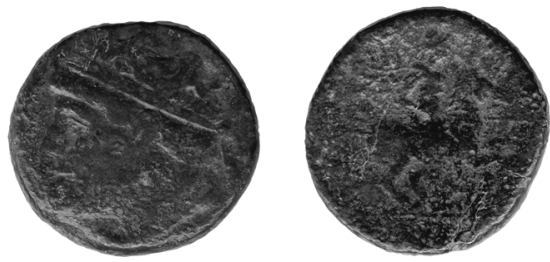

$5(4)$
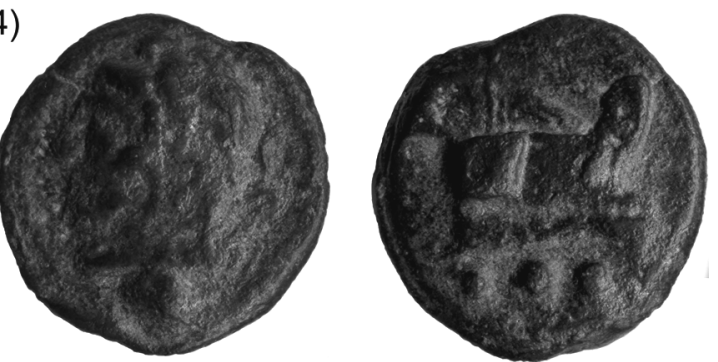

$6(5)$
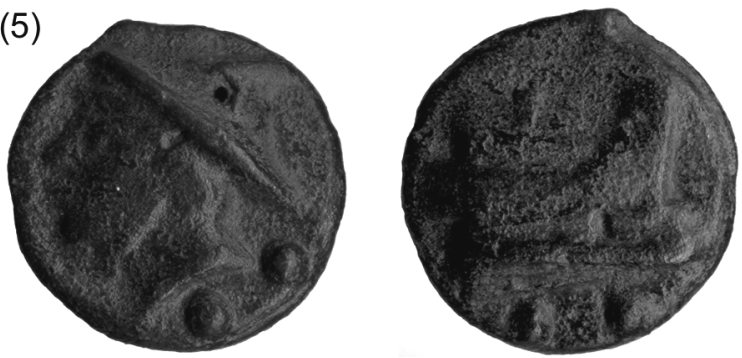

$7(6)$
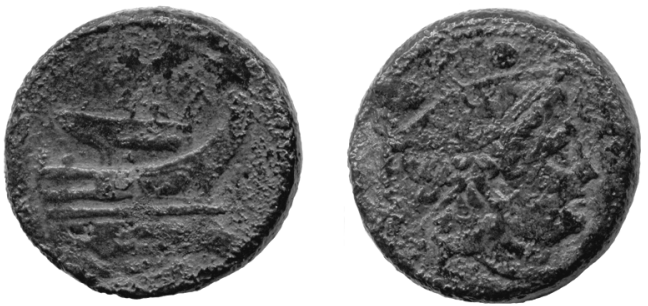

$11(24)$

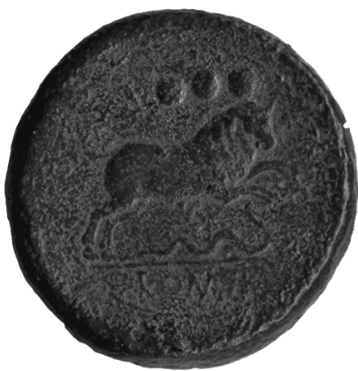

Fig. 6. Monedas de la Palma amortizadas a finales del siglo III a.C. (entre paréntesis, el $\mathrm{n}^{\circ}$ de inventario): 1. Neapoliton (Taliercio, 1986, grupo IIIa, serie 4); 2. Hierón II de Siracusa. Monedas de la República romana anteriores al 211 a.C. 3 . Didracma RRC 13/1; 4. Cuadrigato RRC 28/3; 5. Quadrans RRC 35/4; 6. Sextans RRC 35/5; 7. Sextans RRC 38/5; 8. Semiuncia RRC 38/7; 9. Semiuncia RRC 39/5; 10. Uncia RRC 38/6; 11. Quadrans RRC 39/2; 12. Uncia RRC 39/4. Escala 1:1. 
$1(77)$
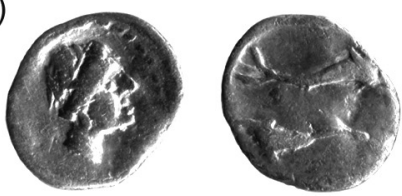

$3(79)$

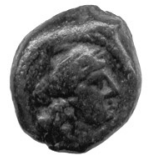

$4(80)$
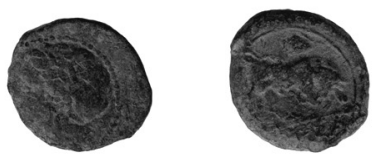

$6(74)$
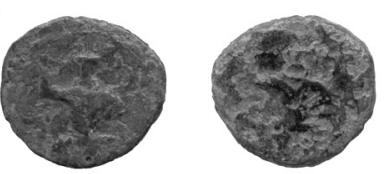

$8(66)$
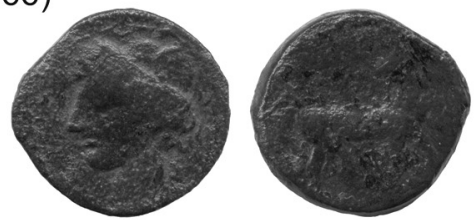

$9(59)$
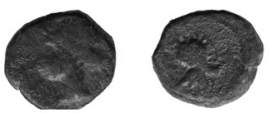

$11(64)$
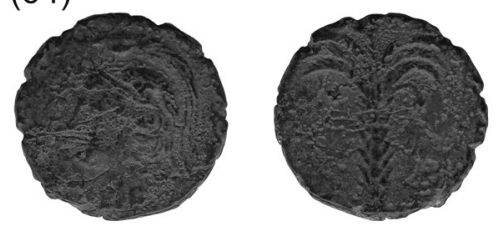

$13(65)$
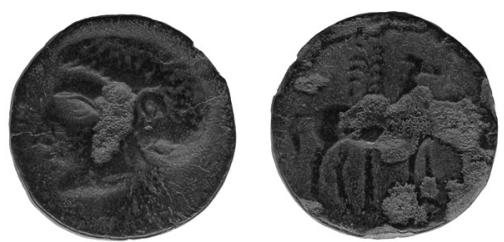

$2(78)$
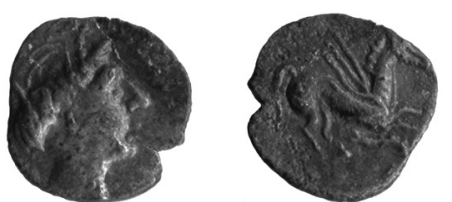

$5(90)$
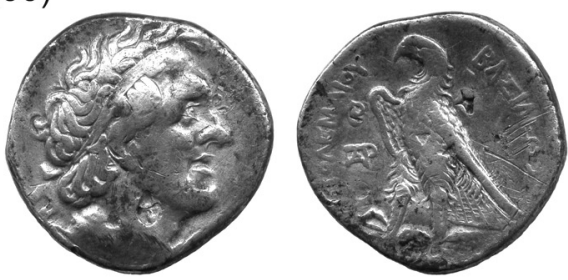

$7(73)$
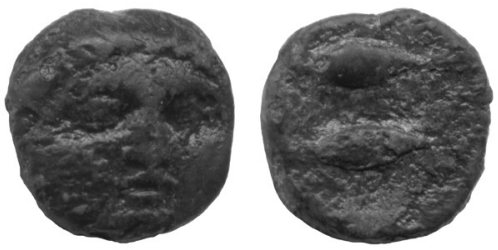

$10(43)$
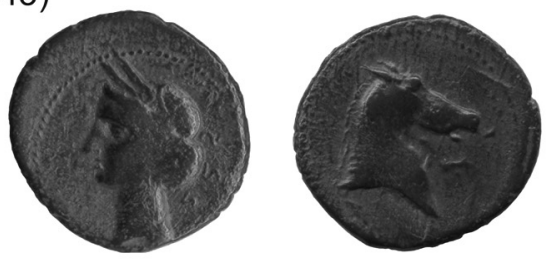

$12(55)$
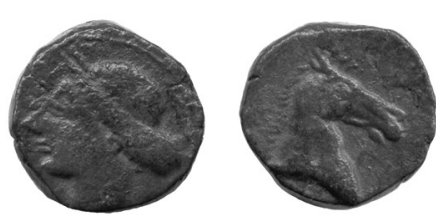

$14(61)$
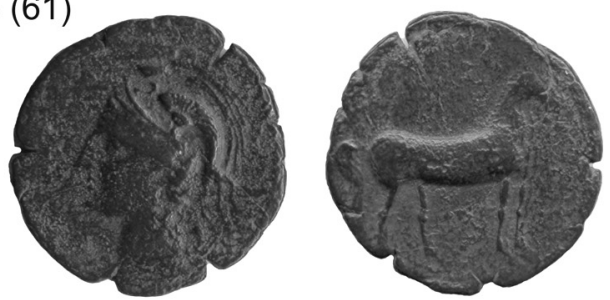

Fig. 7. Monedas de la Palma amortizadas a finales del siglo III a.C. (entre paréntesis, el $\mathrm{n}^{\circ}$ de inventario): 1. Divisor de Emporion; 2. Imitación ibérica; 3-4. Bronces de Massalia; 5. Tetradracma helenística de Ptolomeo I o II; 6. Unidad de Ebusus (Campo, 1976, 50); 7. Divisor de Gadir; 8. Shekel de Cartago (Alexandropoulos, 2000, $\mathrm{n}^{\circ}$ 90). 9-14: Monedas hispano-cartaginesas (Villaronga, 1973). 9. $\mathrm{n}^{\circ} 117 ; 10 . \mathrm{n}^{\circ} 110 ; 11 . \mathrm{n}^{\circ} 126 ; 12 . \mathrm{n}^{\circ} 116 ; 13 . \mathrm{n}^{\circ} 258-275 ; 14 . \mathrm{n}^{\circ} 123$. Escala 1:1. 


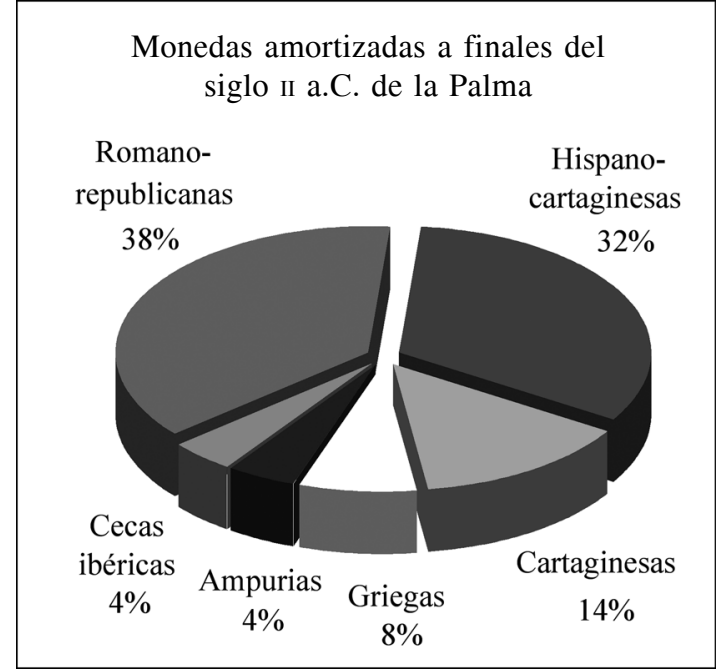

Fig. 8. Procedencia de las monedas del campamento romano de la Palma.

estos momentos, reflejada en la rebelión de los soldados romanos del campamento de Sucro en el 206 a.C. a causa del impago de su salario, a pesar de que el mismo Escipión ocasionalmente les hubiera retribuido con los bienes conseguidos sobre el terreno (Polibio XI, 28, 3-6). Por lo tanto, la ausencia de monedas de la serie del denario en la Palma confirmaría la hipótesis de su llegada a la Península después del 206 a.C. (García-Bellido 1993, 332).

En definitiva, es posible que la diversidad y la procedencia del conjunto responda al numerario que había en circulación en la península itálica antes del 211-209, sumadas a las acuñadas en la península Ibérica, ya sea indígenas, griegas, púnicas e incluso quizás acuñaciones romanas.

Evidentemente, la importancia del campamento residía en el control de la desembocadura del Ebro, un lugar de alto valor estratégico y paso obligado de los ejércitos que utilizaron la vía Heraklea en sus desplazamientos. Esta zona fue escenario de los diversos intentos cartagineses por expulsar a los romanos y hacer llegar refuerzos y suministros a las tropas de Aníbal en la península itálica (Fig. 9). En el 217 a.C. se produce la derrota naval cartaginesa en la desembocadura del Ebro, en el 216 la batalla próxima a Hibera (Tortosa?) y en el 215 Intibilis (la Jana?). Poco a poco los combates se van desplazando hacia el sur y es posible que en el 212 los romanos tomasen Sagunto. Dada la proximidad y la importancia de la cuenca del Júcar para internarse hacia el interior de la Península y, por ende, al alto Guadalquivir, no podemos descartar que el campamento de Sucro se estableciese por estas fechas. Así, se perfilaría un avance romano por etapas, dejando bases en la retaguardia, por lo que no creemos que los dos Escipiones osaran internarse en el alto Guadalquivir antes del 212, ya que para ello habían de contar con una serie de campamentos y guarniciones que jalonaran el camino. De hecho, después del descalabro en el sur, L. Marcio y T. Fonteyo consiguen reconstruir un ejercito reuniendo tropas estacionadas en diversos destacamentos (Livio $\mathrm{XXV}, 37,4-5)$ y retirarse a las posiciones originales del año 217. Es en estos momentos cuando se produce la primera mención de la existencia de un campamento en el río Ebro, en principio geográficamente imprecisa: ...se acordó elegir un jefe del ejército en los comicios militares después de fortificar el campamento al lado de acá del Ebro, relevándose unos a otros en la vigilancia de la empalizada y en los puestos de guardia... (Livio XXv, 37, 6-7; trad. J. A. Villar). Posteriormente, la llegada de refuerzos al mando del propretor Claudio Nerón permite concretar su localización junto al río: Este ejército embarcó en Puteólos y Nerón lo condujo a Hispania. Llegó a Tarragona con las naves, desembarcó allí las tropas, y después de varar las naves armó también a las tripulaciones para incrementar el número de tropas; partió hacia el Ebro y se hizo cargo del ejército de Tiberio Fonteyo y Lucio Marcio (Livio XXVI, 17, 2-3; trad. J. A. Villar). Finalmente, la concentración de tropas y naves ordenada por Escipión Africano en el 209 a.C. precisa su localización en la desembocadura: En Hispania, a principios de la primavera, Publio Escipión botó al mar sus naves y mediante un edicto citó en Tarragona a las fuerzas aliadas auxiliares, y ordenó a la flota y las naves de transporte dirigirse de allí a la desembocadura del río Ebro. Después de dar orden de que acudieran también allí las legiones desde los cuarteles de invierno, él salió de Tarragona con cinco mil aliados para unirse al ejército (Livio XXVI, 41, 1-2; trad. J. A. Villar). Un comentario posterior de T. Livio, en boca de Fabio Máximo, recuerda la llegada de Escipión a Hispania y confirma la localización de un gran campamento junto a la desembocadura del río: Navegando a lo largo de las costas de Italia y de la Galia en un mar libre de enemigos abordaste con tu flota a Ampurias, una ciudad aliada; desembarcadas las tropas, las condujiste hacia unos aliados y amigos del pueblo romano, a Tarragona, por parajes que no ofrecían el menor peligro; posteriormente la marcha desde Tarragona fue atravesando guarniciones romanas; junto al Ebro estaban los ejércitos de tu padre y de tu tío... (Livio XXVIII, 42, 3-4; trad. J. A. Villar).

Por lo tanto, creemos que las consideraciones geoestratégicas, los indicios arqueológicos y las fuen- 


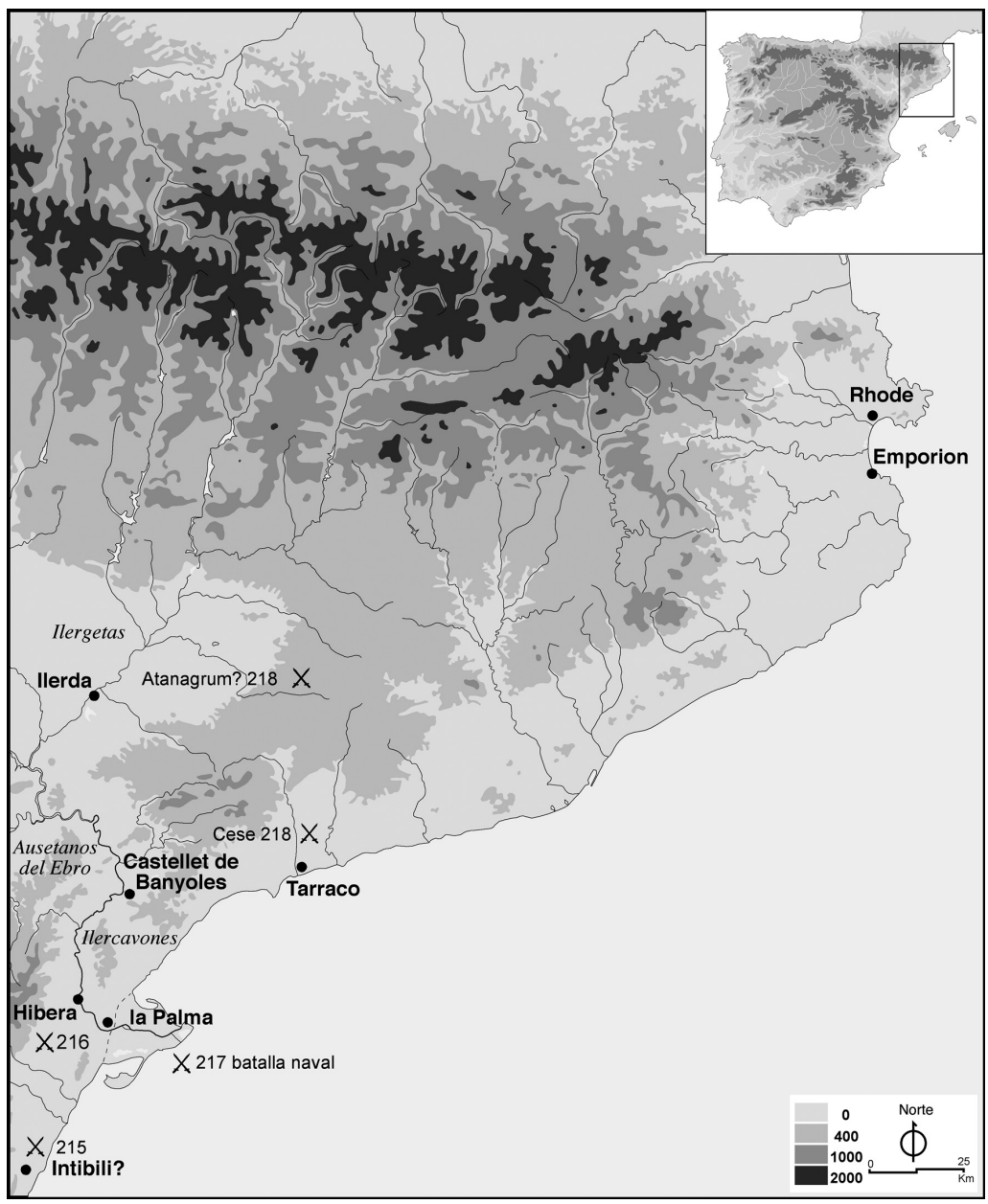

Fig. 9. Mapa del noreste de la península ibérica, con las poblaciones, enfrentamientos bélicos y tribus iberas citadas en el texto.

tes escritas sugieren que fue en la Palma donde Escipión reunió el ejército y la flota antes de su ataque simultáneo sobre Cartago Nova. Su conquista representó un cambio de signo definitivo en la contienda que libraban romanos y cartagineses en la Península. Los combates se desplazarán al sur, y por ello el asentamiento militar de la Palma perdería paulatinamente protagonismo hasta el fin del conflicto.

\section{LOS ENFRENTAMIENTOS CON LOS PUEBLOS IBÉRICOS DEL VALLE DEL EBRO}

Inmediatamente después de ser derrotados y expulsados los cartagineses de la Península en el 206 a.C., Escipión tuvo que enfrentarse al primer levantamiento indígena, encabezado por la tribu de los ilergetas comandados por Indíbil y Mandonio, a los que se añadieron otras tribus colindantes (Polibio XI, 32; Livio XXVIII, 24, 3-4). La insurrección fue sometida pero al año siguiente se reprodujo liderada por los mismos protagonistas. Los procónsules L. Cornelio Léntulo y L. Manlio Acidino atravesaron el territorio ausetano para someter a los sublevados, concentrados en territorio sedetano (Livio XXIX, 2, 12). En el 200 a.C. nuevamente el procónsul C. Cornelio Cetego obtiene una victoria en territorio sedetano (Livio Xxxi, 49, 7). En el año 197 el procónsul C. Sempronio Tudetano es derrotado y muerto en un lugar indeterminado de la nueva provincia de la Hispania citerior (Livio XXXIII, 25, 8-9). En este período se produce una sublevación generalizada que provoca el desembarco en Ampurias de un ejército consular al mando de M. Porcio Catón (Livio XXXIV, $8,4)$. A pesar de la victoria inicial y de sus esfuerzos no parece que la sublevación se pueda dar por 


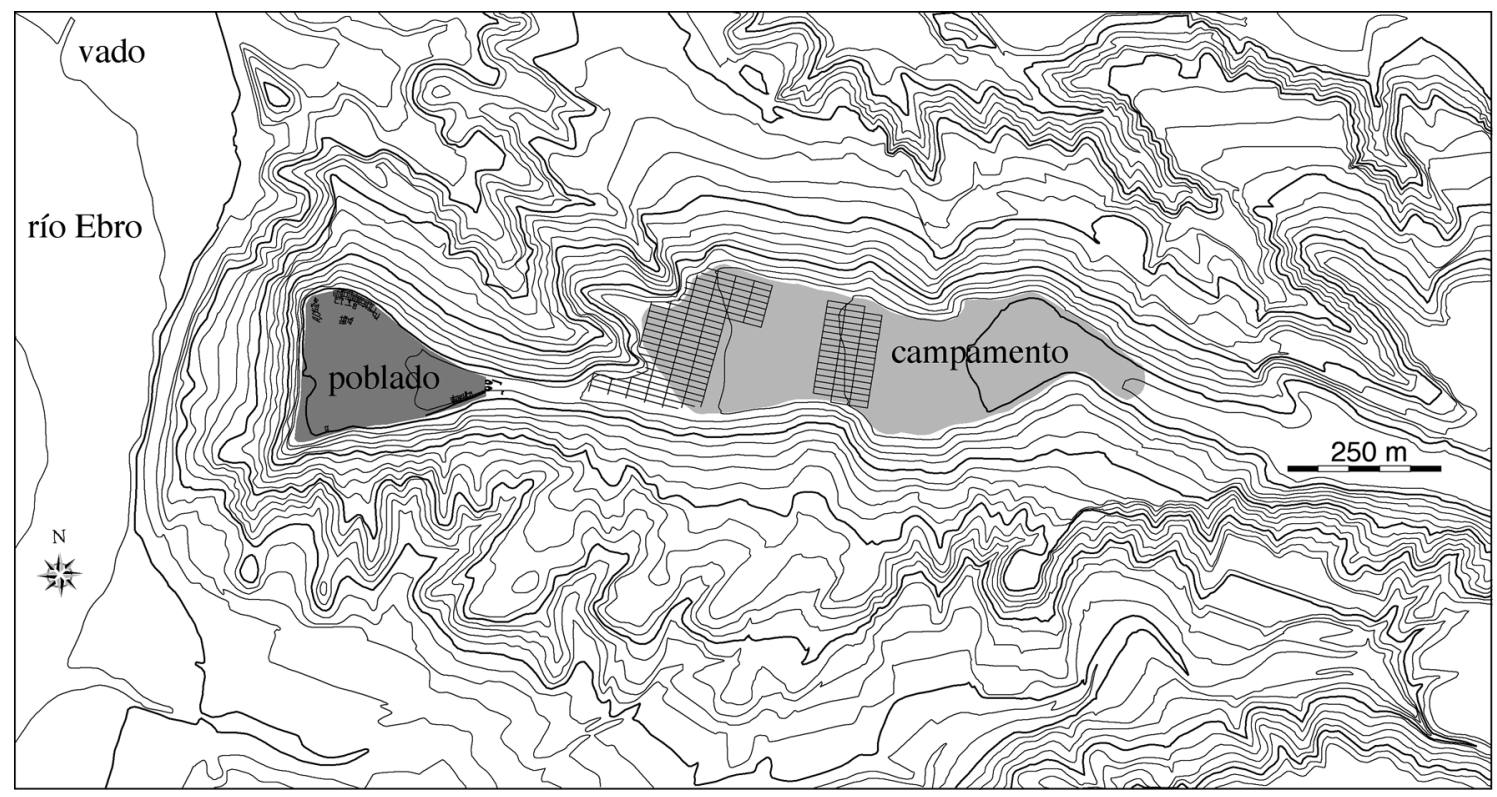

Fig. 10. Situación del poblado ibérico y del campamento en el Castellet de Banyoles, junto al río Ebro, con las unidades de prospección de la campaña de 2007.

extinguida ya que el mismo cónsul ha de someter nuevamente a los sedetanos, ausetanos y suesetanos (Livio XXXIV, 20, 1). Incluso la represión de Catón no fue definitiva ya que después de su marcha el pretor S. Digicio perdió la mitad de sus tropas ( $\mathrm{Li}$ vio $\mathrm{XXXV}, 1,1-2)$.

De los hechos narrados por las fuentes podemos sacar varias conclusiones. En primer lugar, que en los primeros años del siglo II a.C. se produjeron incesantes rebeliones indígenas contra los romanos y probablemente habría que añadir otras que no quedaron reflejadas por escrito. Igualmente hay que constatar la fragilidad de los tratados de paz establecidos seguramente porque en la mayoría de las ocasiones incluían unas condiciones muy severas para los indígenas. También parece evidente que el principal escenario de los combates fue el interior del valle del Ebro, en tierras de los ausetanos, ilergetas, sedetanos y suesetanos. Finalmente, hay que suponer que si Tarraco continuaba siendo la principal base de operaciones romana, muchas de sus incursiones se habrían realizado atravesando el territorio de los ilercavones, en el bajo Ebro (Fig. 9).

En este contexto el poblado del Castellet de Banyoles (Tivissa, Ribera d'Ebre) adquiere una gran importancia geoestratégica. Se trata del mayor asentamiento ibérico al sur de Cataluña, un oppidum ilercavón de 4,2 ha que controla el curso del Ebro a su paso por la depresión de Móra, así como la vía de acceso que, desde el interior del bajo Aragón, territorio ausetano, se dirige hacia la costa y por ende hacia Tarraco. De hecho, está justo encima del vado que facilita el paso del río siguiendo esta ruta (Fig. 10).

Desde principios del siglo Xx se han sucedido los hallazgos fortuitos y espectaculares. Los llamados tesoros de Tivissa están formados por páteras, pendientes, colgantes, brazaletes y anillos de oro y plata, así como monedas de plata y bronce. A raíz de estos descubrimientos entre los años 1929 y 1943 se realizaron las primera intervenciones arqueológicas, con la excavación de las dos torres pentagonales que protegen la entrada y de un barrio junto al acceso (Serra Ràfols 1941; Vilaseca, Serra Ràfols, Brull 1949; Serra Ràfols 1964-65). Con posterioridad se realizó alguna intervención puntual y se halló un nuevo tesoro.

Probablemente hay que relacionar la abundancia de objetos de plata y plomo con la proximidad de las minas de galena argentífera situadas en la cuenca del río Siurana. Así lo sugiere el hallazgo de hornos y toberas destinados a la transformación del mineral (Vilaseca 1945, 80; Asensio, Miró, Sanmartí 2005, $621)$, e incluso se ha propuesto que el Castellet de Banyoles pudo acuñar moneda de plata (TarradellFont 2003-04).

Desde 1998 se suceden las excavaciones programadas (Asensio, Miró, Sanmartí 2002; Asensio, Miró, Sanmartí 2005), confirmando un nivel homogéneo de 
a) Porcentaje de material cerámico del campamento del Camí del Castellet de Banyoles

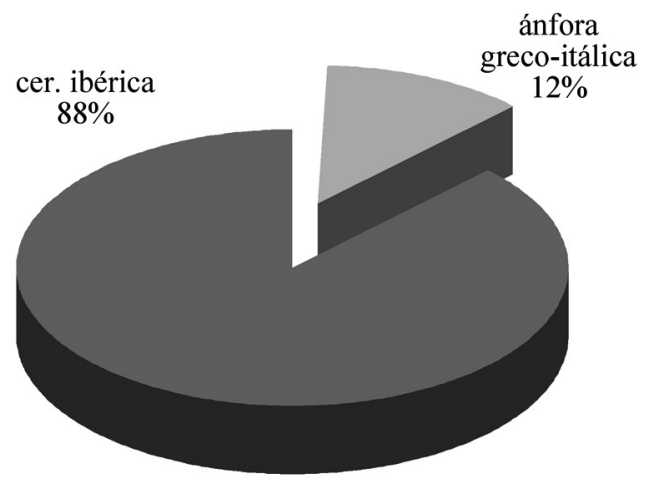

b) Porcentaje de material cerámico del poblado del Castellet de Banyoles

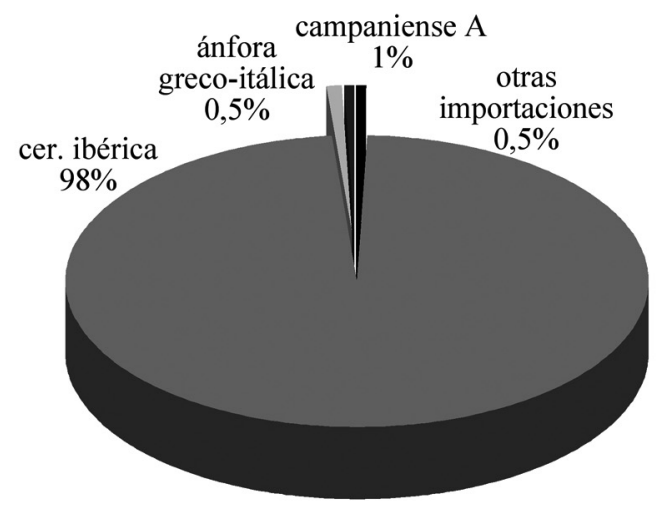

Fig. 11. a) Porcentaje del material cerámico recuperado en la prospección del Camí Castellet de Banyoles (campaña de 2007). b) Porcentaje del material cerámico recuperado en las excavaciones del poblado ibérico del Castellet de Banyoles (campañas 1998-2005).

destrucción datado a finales de siglo III o inicios del siglo II a.C., aunque parece que existió una cierta reocupación de carácter desconocido a finales de siglo II y durante el siglo I a.C. La fase de finales del siglo III a.C. está caracterizada por un urbanismo denso y complejo con casas de diferentes tamaños y calles amplias. Se han descubierto plomos con escritura ibérica y han aparecido más joyas y monedas. Todo ello indica una estructura económica y administrativa organizada, propia de un gran centro de poder político que controlaba el territorio circundante (Noguera 1998).

Pero nuestro interés se centra ahora en el yacimiento recientemente localizado más allá del angosto paso de cinco metros de anchura y cien metros de longitud que restringe el acceso al poblado, el Camí del Castellet de Banyoles (Noguera 2007, 314). Ocupa una extensa plataforma de $11 \mathrm{Ha}$, prácticamente llana, delimitada al oeste por el estrecho paso adyacente a las torres del poblado y al este por un segundo estrangulamiento de apenas veinte metros de anchura (Fig. 10).

La prospección arqueológica realizada el mes de noviembre de 2007 ha incidido sobre 4,3 Ha., siguiendo uno de los dos métodos utilizados en el yacimiento de la Palma, es decir, la prospección sistemática de unidades de $300 \mathrm{~m}^{2}$, de manera que los resultados pudieran ser comparados. Los materiales aún están en estudio, pero podemos avanzar algunos datos que creemos significativos. Así, por ejemplo, en toda la superficie prospectada se recuperaron fragmentos cerámicos ibéricos e itálicos, excepto en la hectárea de terreno inmediata a la entrada al poblado, de manera que creemos que esta zona nunca fue ocupada. De los 708 fragmentos recuperados en los campos más alejados, el $88 \%$ corresponden a cerámica ibérica, mayoritariamente material de transporte y almacenaje, mientras que el $12 \%$ son fragmentos de ánforas greco-itálicas. La presencia de cerámica a mano o vajilla campaniense A es ínfima, casi inexistente (fig. 11a). Las ánforas greco-itálicas son similares a las recuperadas en la Palma, con bordes inclinados unos $45^{\circ}$ (Fig. 12), de finales del siglo III o inicios del siglo II a.C.

La cuantificación presentada es significativa sí la comparamos con el análisis de los materiales procedentes de las excavaciones del interior del poblado (Fig. 11b), donde únicamente el 0,5\% de los fragmentos corresponden a ánforas greco-itálicas y el $1 \%$ a campaniense A, mientras que el $98 \%$ de los fragmentos pertenecen a producciones locales (Jornet 2006). Por lo tanto, creemos que hay que descartar la posibilidad de que el yacimiento sea una continuación extramuros del hábitat. Por el contrario, otros indicios refuerzan la hipótesis de un asentamiento militar, como los 23 glandes de plomo recuperados, siempre sin leyenda (Fig. 13), así como un posible portaestandarte de hierro, un pequeño halcón de plomo y otros objetos metálicos (Noguera en prensa).

Al igual que en la Palma, la prospección no ha identificado restos de construcciones, como tampoco lo hizo la profunda rasa excavada hace pocos años 

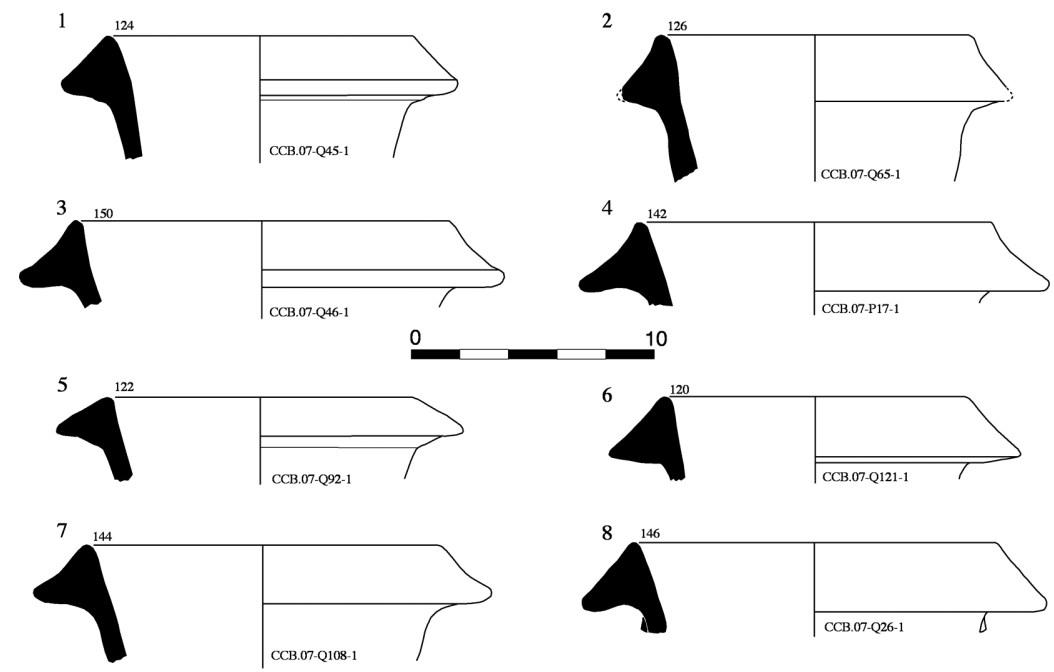

Fig. 12. Fragmentos de ánforas greco-itálicas procedentes del Camí del Castellet de Banyoles (campaña de prospección de 2007).

para renovar el conducto de gas que atraviesa completamente el yacimiento.

Pero quizás el dato más significativo es el lote de 13 monedas de plata y 24 de bronce procedente de colecciones particulares (Tarradell-Font, Noguera en prensa) y de hallazgos fortuitos (Serra Ràfols 1949, 200), al que hemos añadido un tetartemorion de Emporion recuperado durante la campaña de prospección de 2007. Seis de las piezas de bronce aún no han podido ser consultadas, pero probablemente se trate de monedas romano-republicanas. En cualquier caso, el resto de las piezas, excepto tres, pertenecen a emisiones encuadradas cronológicamente entre la Segunda Guerra Púnica y los primeros levantamientos de los iberos.

La mayoría de las monedas son romano-republicanas (Fig. 14). Las presentamos divididas en varios lotes según la cronología de sus emisiones y el metal de que están compuestas: el primer lote consta de 4 bronces anteriores a la aparición del denario, el segundo está formado por 16 monedas de plata y bronce del 211-208 a.C., mientras que el tercer lote lo componen 3 bronces del siglo II a.C.

Los cuatro bronces romano-republicanos anteriores al denario, de la serie semi-libral de los años 217215 a.C., son una uncia y tres semiuncias (Fig. 15, 5). Estas piezas son muy escasas en Cataluña, a excepción del yacimiento de la Palma.

De las dieciséis monedas del 211-208 a.C., nueve son monedas de plata de la República romana. Se trata de 2 victoriatos, 3 denarios, 1 quinario y 3 sestercios (fig. 15, 1-4). Estas emisiones concuerdan cronológicamente con las emisiones romano-republicanas ha- lladas en el poblado del Castellet de Banyoles (Tarradell-Font 2003-04), con la diferencia de que allí sólo se han hallado denarios y victoriatos; mientras que en el Camí del Castellet de Banyoles se han recuperado divisores de plata: un quinario y tres sestercios. Las siete monedas romanas restantes de finales del siglo III a.C. son de bronce: tres ases (fig. 15, 6), un semis, dos triens (Fig. 15, 7) y un sextans. Cuatro de estas piezas fueron acuñadas en Cerdeña y una de ellas reacuñada sobre un bronce sardo-púnico (Fig. 15, 8), hecho bastante frecuente en el nominal sextans de estas emisiones (Crawford 1974, 13), mientras que las otras tres son de la emisión anónima RRC 56.

Completan el conjunto unas pocas monedas emitidas en la Península: una dracma (Fig. 15, 9) y un tetartemorion de Ampurias, dos dracmas de imitación ibérica de Ampurias (Fig. 15, 10) y un bronce de Neápolis (Campania). Ésta última es una pieza de la serie Cabeza masculina/Jinete (Fig. 15, 11), realmente excepcional y correspondiente a las últimas emisiones de la ciudad. Los pocos ejemplares que conocemos son de la serie Cabeza de Apolo/Toro androcéfalo, como los encontrados en el campamento romano de la Palma.

Finalmente, las monedas del siglo II a.C. son poco numerosas, únicamente tres bronces RRC (aunque alguno de los inclasificables o aún no clasificados también podrían ser de esta época) y un ejemplar ibérico de la ceca de Lauro. Cronológicamente es un lote que se desmarca de los anteriores y hay que relacionarlo con los bronces ibéricos recogidos en los niveles superficiales del poblado. Seguramente proceden de una reocupación posterior del asentamien- 


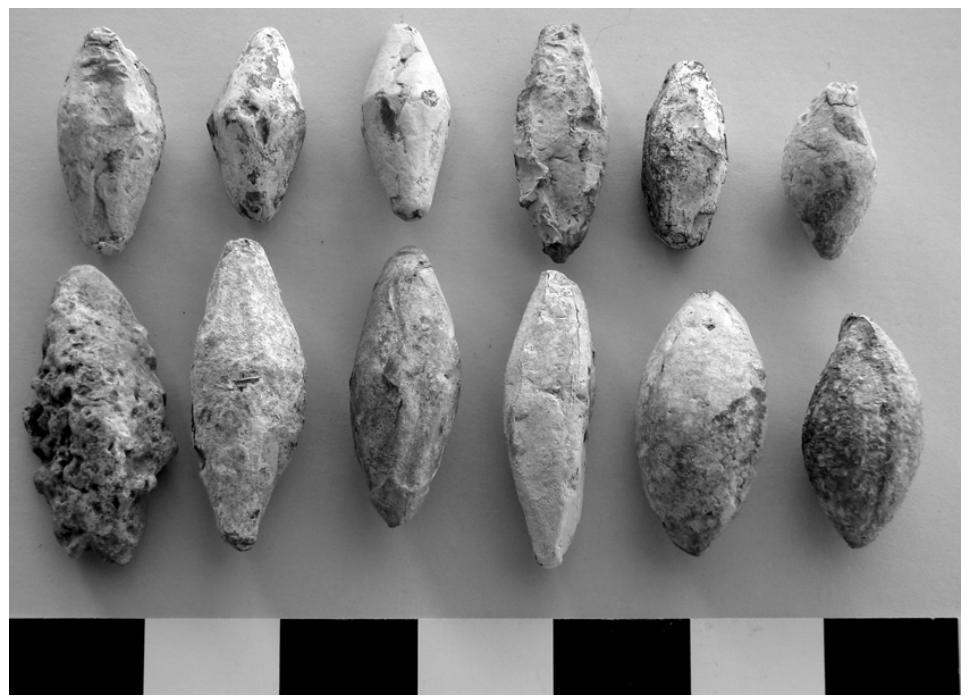

Fig. 13. Glandes de plomo procedentes del Camí del Castellet de Banyoles.

to, fechada a partir de finales del siglo II a.C., pero con unas estructuras constructivas actualmente casi arrasadas (Asensio, Miró, Sanmartí 2002).

Como podemos observar, la principal diferencia entre el conjunto de monedas procedente del interior del poblado ibérico y el conjunto de monedas procedente del campamento del Camí del Castellet de Banyoles es el lote de monedas de bronce romano-republicanas acuñadas a finales del siglo III a.C. Hasta el momento en el hábitat ibérico no se ha hallado ningún ejemplar. De hecho, habitualmente, estas monedas se relacionan con la presencia de tropas romanas como es el caso del campamento de la Palma.

Monedas amortizadas a inicios del siglo II a.C. del Camí del Castellet de Banyoles

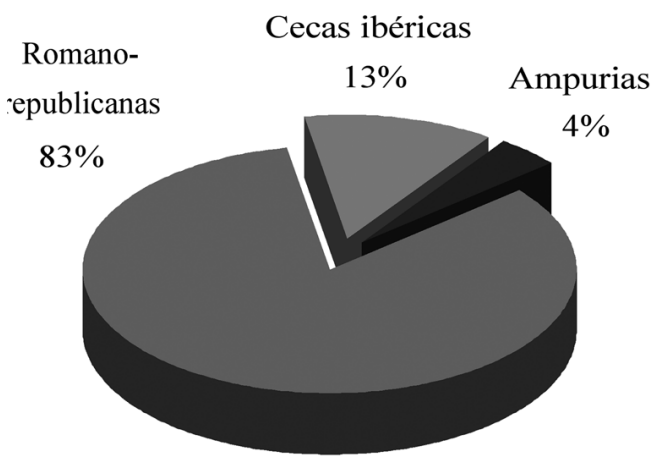

Fig. 14. Porcentaje de las monedas procedentes del campamento del Camí del Castellet de Banyoles.
La cronología del poblado y del campamento del Castellet de Banyoles viene dada por la presencia de victoriatos, denarios, sestercios y quinarios, lo cual permite datar ambos yacimientos con posterioridad al 211-209 a.C., la fecha de inicio de acuñación. Pero como hemos comentado, parece que estas últimas monedas no circularon en la Península durante la Segunda Guerra Púnica. Además hay que recordar que en la Palma abunda el numerario del bando púnico, mientras que en el Camí del Castellet de Banyoles es inexistente. Estas monedas debieron ser retiradas de circulación después de la derrota y retirada cartaginesa, por lo que hay que suponer que su ausencia es debido a que el yacimiento es posterior al 206 a.C., e incluso creemos más apropiada una fecha entre el 200 y 190 a.C., ya que había de transcurrir un cierto tiempo hasta conseguir retirar la totalidad del numerario púnico. Este período se ciñe mejor al momento en que los romanos someten a las tribus ibéricas del interior del valle del Ebro.

En el estado actual de la investigación no podemos afirmar si el campamento localizado fue el que acabó destruyendo el oppidum del Castellet de Banyoles, ya que también se podría tratar de un destacamento aliado, sobre todo por su proximidad al poblado. Pero existen algunos indicios que podrían sugerir lo contrario. Así, por ejemplo, la cronología del campamento es coincidente con la destrucción del hábitat, un hecho ya de por sí a tener en cuenta. En segundo lugar, la existencia de una «tierra de nadie» de 300 metros de longitud entre ambos yacimientos (una distancia demasiado reducida, todo hay que decirlo). 
$1(6)$
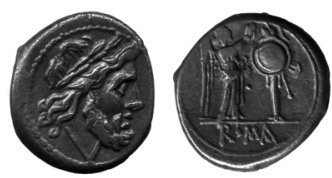

$3(7)$

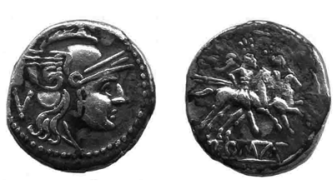

5 (3)

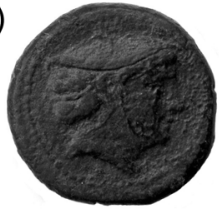

6 (16)

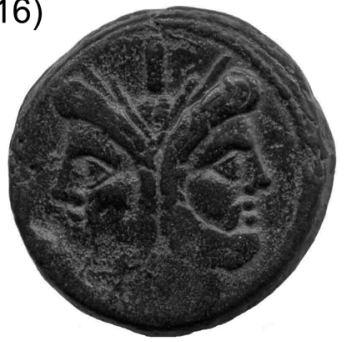

7 (20)
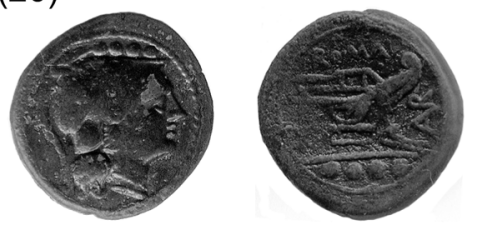

9 (31)
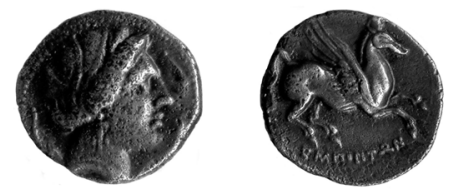

2 (12)

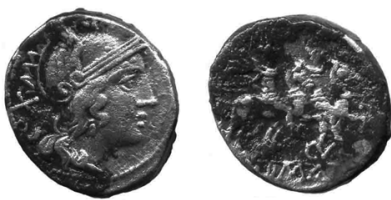

4 (9)

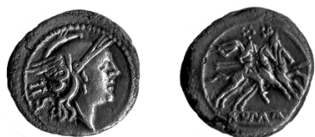

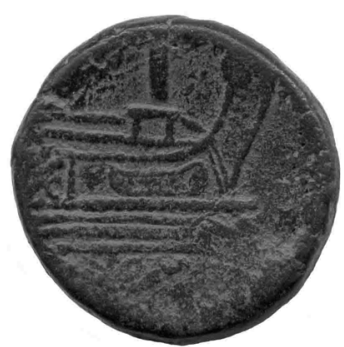

8 (19)

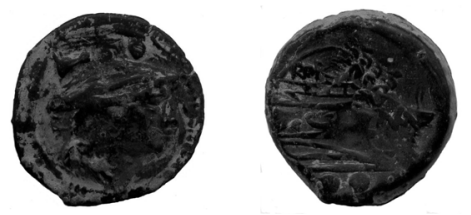

$10(33)$
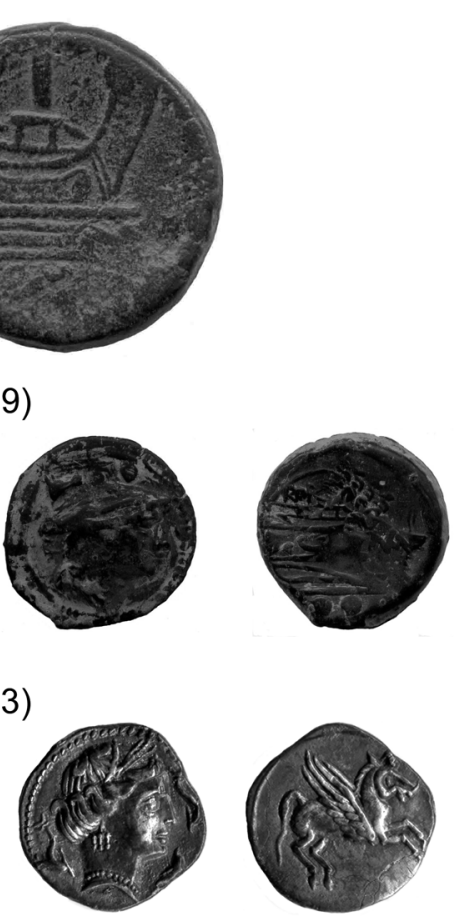

$11(35)$
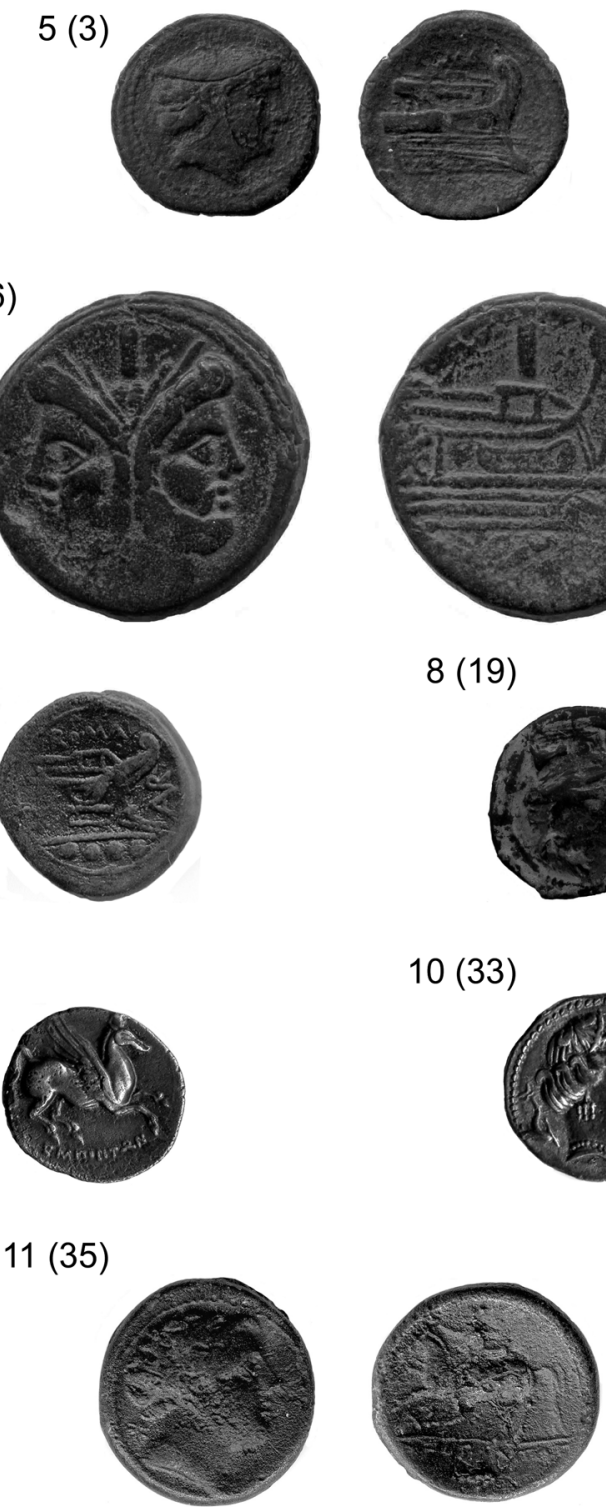

Fig. 15. Monedas del Camí del Castellet de Banyoles de finales del siglo III a.C. (entre paréntesis, el no de inventario) 1. Victoriato, RRC 44/1, 211 a.C.; 2. Denario, RRC 74/1, C.VAR, 209-208, Sicilia; 3. Quinario, RRC 44/6, 211 a.C.; 4. Sestercio, RRC 44/7, 211 a.C.; 5. Semiuncia, RRC 38/7, 217-215; 6. As, RRC56/2, posterior al 211; 7. Triens, RRC 65/4, AVR, Cerdeña, 209 a.C. ; 8. Sextans, RRC 64/6c, MA, Cerdeña, 210 a.C. ; 9. Dracma de Ampurias (Villaronga 2003, grupo 3, CNHAAA p. 22 n. ${ }^{\circ}$ 37); 10. Dracma ibérica de imitación; 11. Bronce de Neápolis, mitad (Taliercio Fase IV b, serie 8). Escala 1:1. 
En tercer lugar, la diferencia significativa en los porcentajes cerámicos y en los conjuntos numismáticos sugieren dinámicas de aprovisionamiento diferentes para los dos yacimientos. Finalmente, muchos de los glandes de plomo fueron recuperados en la vertiente norte del poblado, mientras que no se ha documentado ninguno en las vertientes sur y oeste. Ello conduce a pensar en un ataque por la vertiente más accesible, evitando el acceso angosto y bien fortificado.

Para acabar, el alto porcentaje de material ibérico recuperado en superficie podría hacernos pensar que estamos ante un asentamiento militar con tropas indígenas auxiliares. Pero en este caso no creemos que el material sea definitorio ya que, en palabras del mismo Catón, «bellum se ipsum alet» (Livio XxxIV, 9,12 ), por lo que el ejército romano se abastecería sobre el terreno, de manera que creemos lógico recuperar material de transporte y almacenaje local en un campamento legionario.

\section{LOS ASENTAMIENTOS MILITARES \\ DE LA PALMA Y DEL CAMÍ DEL CASTELLET \\ DE BANYOLES. HACIA UN MODELO DE CAMPAMENTO DE CAMPAÑA DE INICIOS DE LA CONQUISTA ROMANA}

A partir de la documentación presentada creemos pertinente realizar una serie de reflexiones mediante la comparación de los datos recuperados en estos y otros asentamientos similares:

- Los campamentos de campaña presentan una densidad muy baja de material cerámico en superficie. Por ejemplo, durante la prospección de la Palma se recogieron 125 fragmentos cerámicos por hectárea (118 frag./Ha. en la zona B1 y 129 frag./Ha. en la zona B2, utilizando diferentes métodos de prospección), mientras que en el Camí del Castellet de Banyoles se recuperaron 163 fragmentos cerámicos por hectárea, por lo tanto estamos ante concentraciones de material similares.

- La dispersión de estos materiales es muy elevada, originalmente unas $30 \mathrm{Ha}$ en la Palma, 9 ha en el Camí del Castellet de Banyoles, 10 Ha. en los Planos de Mara y quizás más de 100 Ha. en el Cerro de las Albahacas. Es evidente que estamos ante concentraciones de tropas importantes. A título de ejemplo, se ha calculado que una legión en época imperial ocuparía una extensión cercana a las $20 \mathrm{Ha}$. (Mori1lo 2003, 70).

- Ninguno de los campamentos de campaña mencionados (a excepción de los campamentos numantinos, con una problemática específica) ha proporciona- do restos de estructuras constructivas. Éste es un aspecto que muy probablemente viene determinado por el tipo de materiales empleados y por la remoción de los suelos producida por los trabajos agrícolas. En el caso de los yacimientos estudiados en el bajo Ebro, estamos convencidos de que el suelo original ocupado por las legiones romanas ya ha desaparecido, de manera similar a la documentada en los Planos de Mara (Burillo 2007, 285). Así se explica que en un mismo estrato removido recuperemos monedas de finales del siglo III a.C., imperiales, medievales o modernas. La única posibilidad para documentar contextos arqueológicos cerrados probablemente pase por identificar depósitos naturales o depresiones artificiales donde se conserven materiales de la época, como los documentados alrededor del Mont Auxois durante la batalla de Alesia (Reddé et alii 2001).

- La vajilla itálica propia del momento, la cerámica campaniense A, es minoritaria, casi inexistente. No se ha recuperado ningún fragmento en la Palma, apenas cuatro en el Camí del Castellet de Banyoles y según referencias del investigador principal del proyecto de Ségeda, son también muy escasas en los Planos de Mara ${ }^{6}$. Es evidente que los legionarios no realizaban largas y duras marchas carga-dos con frágiles platos o vasos de cerámica, sino que con el equipo debían transportar recipientes más resistentes, de piel, madera o metal. La ausencia de vajilla en los campamentos legionarios se repite en los castra aestiva de las guerras cántabras, donde no se ha documentado cerámica sigilada (Peralta 2002).

- En la misma línea, también queremos destacar que no hemos recuperado ningún tipo de cerámica de cocina. La dieta básica de las tropas debía ser el pan, la polenta y la carne asada o cocida, de manera que los utensilios debían ser fácilmente transportables, ligeros y resistentes, lo que evidentemente excluye la cerámica (Herreros, Santapau, Sanfeliu 2006).

- En cambio, la mayoría de los fragmentos recuperados pertenecen a materiales de transporte y almacenaje. Así, en la Palma el $66 \%$ de los fragmentos cerámicos recuperados pertenecen a ánforas grecoitálicas, mientras que en el Camí del Castellet de Banyoles son un $12 \%$. Evidentemente, en el primer caso estamos ante un campamento situado en un punto donde las naves de transporte romanas descargarían directamente sus avituallamientos. Pero aún así, el resto de materiales de procedencia local mayoritariamente también son ánforas y tinajas, tanto en la Palma como en el Camí del Castellet de Banyoles.

\footnotetext{
${ }^{6}$ Agradecemos al Dr. Burillo esta información.
} 
- Algunos de los bordes de ánfora greco-itálica de la Palma o del Camí del Castellet de Banyoles posee un perfil antiguo, pero la diferencia formal quizás no sea debida a una diferencia cronológica, sino a la diversidad de alfares de fabricación (Asensio, Martín 1998, 142). Por lo tanto, no parece un elemento muy útil para diferenciar entre yacimientos de la Segunda Guerra Púnica o de inicios del siglo II a.C.

- La recuperación de glandes de plomo en ambos yacimientos es habitual. En el Camí del Castellet de Banyoles son especialmente numerosos, quizás como consecuencia de la hipotética batalla librada contra el oppidum. En este sentido, creemos interesante destacar que el alcance efectivo de este tipo de proyectil (Quesada 1997, 476) coincide con la separación entre la entrada al poblado y el probable límite del campamento, establecido a partir de la dispersión del material en superficie, unos 300 metros. Creemos también significativo que hasta el momento no hayamos recuperado ningún tipo de punta de flecha, por lo que el arco no parece un arma utilizada por los contendientes.

- La extensión de ambos campamentos permite plantearse la cantidad de tropas albergadas. Así, en el caso de la Palma, las 30 hectáreas identificadas y las llanuras que lo rodean permitirían alojar sin problemas una de las mayores concentraciones de tropas y naves romanas durante la Segunda Guerra Púnica en la Península, los aproximadamente 30.000 soldados comandados por P. Cornelio Escipión justo antes del ataque a Cartago Nova. En el caso de las 9 hectáreas del Camí del Castellet de Banyoles, se trataría de un cuerpo inferior a la legión. La única referencia de las fuentes escritas a las fuerzas de este tamaño a inicios del siglo II a.C. en la zona del Ebro son las siete cohortes comandadas por Catón, aproximadamente unos 3.000 soldados (Livio XXIV, 19, 11), aunque evidentemente podría corresponder a otra situación, no reflejada en las fuentes.

Evidentemente muchas de las ideas propuestas son hipótesis que han de comprobarse en el futuro. El proyecto de investigación aún está en sus fases iniciales de desarrollo ya que hay previstas nuevas campañas de prospección y, llegado el caso, de excavación. En un futuro inmediato también se preve realizar prospecciones geofísicas así como fotografías aéreas en diferentes momentos del día y del año y desde diferentes perspectivas. Igualmente está en marcha el estudio de los objetos metálicos recuperados. Sin duda todo ello redundará en un mejor conocimiento de estos yacimientos y permitirá corroborar, matizar o rechazar muchas de las hipótesis planteadas. Pero creemos que era necesario presentar las novedades cuanto antes, aunque fuera de forma escueta, para permitir avanzar en nuestro conocimiento sobre estos asentamientos militares y sobre los inicios de la conquista romana en la península ibérica.

\section{BIBLIOGRAFÍA}

Alexandropoulos, J. (2000): Les monnaies de l'Afrique Antique 400 av. J.C. - 40 ap. J. C. Presses Universitaires du Mirail, Toulouse.

Asensio, D.; Martín, A. (1998): «El derelicte de Bon Capó (l'Ametlla de Mar): l'inici de l'expansió de vi itàlic a la Península Ibérica», II Col·loqui Internacional d'Arqueologia Romana: El vi a l'antiguitat. Economia, producció i comerç al mediterrani occidental. Monografies Badalonines 14, 138-150.

Asensio, D.; Miró, M.T.; Sanmartí, J. (2002): «El nucli ibèric del Castellet de Banyoles (Tivissa, Ribera d'Ebre): un estat de la qüestió», I Jornades d'Arqueologia. Ibers a l'Ebre. Recerca i interpretació. Ilercavonia 3, 185-203.

- (2005): «Darreres intervencions arqueològiques al Castellet de Banyoles (Tivissa, Ribera d'Ebre): una ciutat ibèrica en el segle III a.C.», Món Ibèric al Països Catalans, XIII Col-loqui Internacional d'Arqueologia de Puigcerdà, vol. I, 615-627.

Bellón, J. A.; Gómez, F.; Gutiérrez, L.; Rueda, C.; Ruiz, A.; Sánchez, A.; Molinos, M.; Wiña, L.; García, M. a A.; Lozano, G. (2004): Baecula. Arqueología de una batalla. Proyectos de Investigación 2002-2003, Universidad de Jaén, 11-66.

Brenot, C. (1982): «Le monnayage de Marseille du IIIe à 49 av. J.C.» Gaule interne et Gaule méditerranéenne aux IIe et Ier siècles avant J.C. Confrontatons chronologiques. Actes de la Table Ronde de Valbonne. Supplement 21, Revue archéologique de Narbonnaise, 31-35.

Burillo, F., (2007): «Los Planos de Mara.», Mori1lo, A. (ed.), El ejército romano en Hispania. Una guía arqueológica. Universidad de León, 282-286.

CAMPo, M. (1976): Las monedas de Ebusus. Barcelona.

García-Bellido, M. P. (1993): «El proceso de monetización en el Levante y sur hispánico durante la Segunda Guerra Púnica», Lengua y cultura en la hispania prerromana. Actas del V Coloquio sobre lenguas y culturas prerromanas de la península ibérica, 317-347.

Herreros, C.; Santapau, M.C.; Sanfeliu, D. (2006): «Vajilla y alimentación en los campamentos numantinos: acerca de las pautas disciplinarias introducidas por Publio Cornelio Escipión Emilia- 
no («Africanus minor»)», Morillo (ed.): Arqueología militar romana en Hispania II: producción y abastecimiento en el ámbito militar, 369-375.

JORNET, R. (2006): Els materials ceràmics vasculars del jaciment ibèric del Castellet de Banyoles ( $\mathrm{T} i$ vissa, Ribera d'Ebre). Estudi tipològic i de quantificació aplicada. Trabajo del Diploma de Estudios Avanzados. Universitat de Barcelona, inédito.

Livio (TRAD. VILlar, J. A.) (1993): Historia de Roma desde su fundación. Libros XXI-XXV; XXVIXXX y XXXI-XXXV. Biblioteca Clásica Gredos 176, 177 y 183. Editorial Gredos, Madrid.

LuIK, M.; MüLLER, D. (2006): «Renieblas, Lager V». Iberia Archaeologica, Band 9.

Lyding WiLL, E. (1982): «Greco-italic amphoras», Hesperia 51-3, 338-357.

Morales, F. (2007) «Circumvallatio de Numantia», Morillo, A. (ed.), El ejército romano en Hispania. Una guía arqueológica. Universidad de León, 263-276.

Morillo, A. (2003): «Los establecimientos militares temporales: conquista y defensa del territorio en la Hispania republicana», Defensa y territorio en Hispania de los Escipiones a Augusto, A. Morillo, F. Cadiou, D. Hourcade (coords.). Universidad de León, Casa de Velázquez, 41-80.

Noguera, J. (1998): «Evolució del poblament de la foia de Móra (Ribera d'Ebre, Tarragona) des del Bronze Final a l'Ibèric Ple: anàlisi i evolució del territori», Revista d'Arqueologia de Ponent, 8, 19-38.

- (2007): L’Ebre ilercavó. Gènesi i evolució de l'estructura del poblament ibèric en el curs inferior del riu Ebre. Universitat de Barcelona. Tesis doctoral en red: www.tdcat.cbuc.es.

- (en prensa): «Los campamentos romanos en el curso inferior del río Ebro durante la Segunda Guerra Púnica». 20th International Congress of Roman frontier Studies. León 2006.

Noguera, J.; TARradell-Font, N. (en prensa): «Noticia sobre las monedas del campamento romano de la Segunda Guerra Púnica de la Palma (l'Aldea, Tarragona)», XIII Congreso Nacional de Numismática, Cádiz 2007.

Peralta, E. (2002): «Los campamentos romanos de campaña (castra aestiva): evidencias científicas y carencias académicas», Nivel cero: revista del grupo arqueológico Attica, 10, 49-87.

Polibio (trad. BALASCH, M.) (1981): Historias. Libros I-IV y I-XV. Biblioteca Clásica Gredos 38 y 43. Editorial Gredos, Madrid.

Quesada, F. (1997): El armamento ibérico. Estudio tipológico, geográfico, funcional, social y simbólico de las armas en la Cultura Ibérica (siglos VI-
I a.C.). 2 vols. Monographies Instrumentum, 3. Ed. Monique Mergoil, Montagnac.

REDDÉ, M. et alii (2001): Fouilles et recherches franco-allemandes sur les travaux militaires romains autour du mont Auxois(1991-1997), Mémoire de l'académie des inscriptions, 2 vol., Paris.

RRC: Crawford, M.H.: Roman Republican Coinage. Cambridge 1974.

Serra RÀFols, J. C. (1941): «El poblado ibérico del Castellet de Banyoles (Tivissa)», Ampurias III, 1534.

- (1949): «Monedes de la República romana, procedents de Tivissa», Ampurias XI, 200-202.

Serra RÀfols, J. C. (1964-65): «La destrucción del poblado ibérico del Castellet de Banyoles, de Tivissa (Bajo Ebro)», Ampurias, XXVI-XXVII, 105 134.

Schulten, A. (1945): Historia de Numancia. Barcelona.

SNG Sassari: Sylloge Nummorum Graecorum. Italia - Sassari. Museo Archeologico «G. A. Sanna». Volume I: Sicilia - Numidia. Ed. Ennerre s.r.l. Milano 1994.

TAliercio, M. (1986): «Il bronzo de Neapolis». La monetazione di Neapolis nella Campania antica. Atti del VII Convegno del Centro Interazionale di Studi Numismatici (Napoli, 20-24 aprile, 1980), Napoli 219-373.

TARradell-Font, N. (2003-2004): «Les monedes del Castellet de Banyoles de Tivissa (Ribera d'Ebre, Catalunya). Noves troballes de les excavacions 1998-1999 i revisió de les anteriors», Fonaments, 10/11, 245-317.

TARradell-Font, N.; Noguera, J. (en prensa): «Avance al estudio de las monedas del Camí del Castellet de Banyoles (Tivissa, Tarragona)». XIII Congreso Nacional de Numismática, Cádiz 2007.

Vilaseca, S. (1945): «A propósito de un hallazgo efectuado en el Castellet de Banyoles (Tivissa) y de las supuestas bocinas de dos ramas, ibéricas y celtibéricas», Butlletí Arqueològic de Tarragona 45, época IV, 74-81.

Vilaseca, S.; Serra Ràfols, J. C.; Brull, L. (1949): «Excavaciones del Plan Nacional en el Castellet de Banyoles de Tivissa (Tarragona)», Informes y Memorias de la Comisión General de Excavaciones Arqueológicas, 20. Madrid.

Villaronga, L. ( 1973): Las monedas hispano-cartaginesas. Barcelona.

- (2003): La plata emporitana de la Segona Guerra Púnica, final del segle III $a C$. Barcelona.

Recibido el 06-03-08. Aceptado el 15-05-08. 